Department for Innovation, Universities \& Skills

\title{
Disabled Students and
}

\section{Higher Education}

Higher Educational Analysis

Department for Innovation, Universities and Skills

DIUS Research Report 0906 


\title{
Disabled Students and Higher Education
}

\author{
Higher Educational Analysis
}

Department for Innovation, Universities and Skills

DIUS Research Report 09-06

(c) Crown Copyright 2009

The views expressed in this report are the authors' and do not necessarily reflect those of the Department for Innovation, Universities and Skills.

May 2009 



\section{Contents}

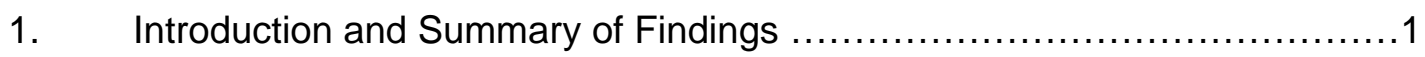

2. Prior Attainment and Attitudes towards Higher Education .................. 3

3. Applicants and Accepted Applicants....................................

4. Participation in Higher Education..........................................

5. Characteristics of Disabled People in Higher Education......................19

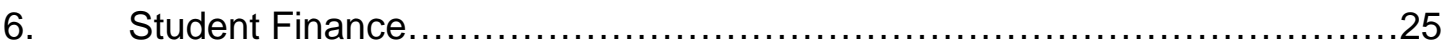

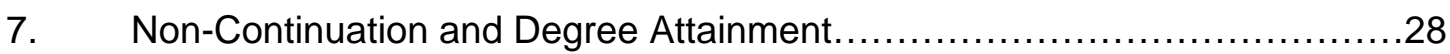

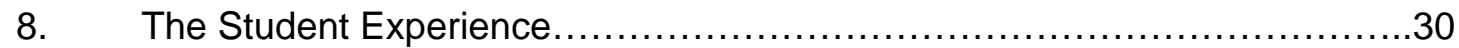

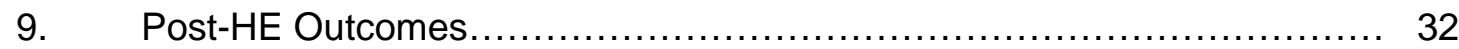

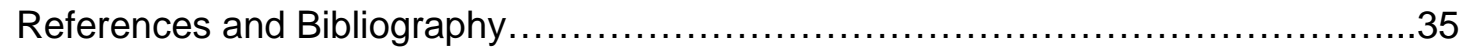

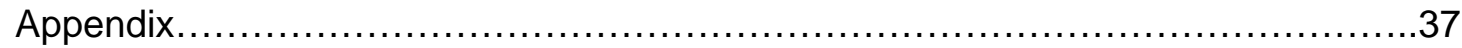




\section{Introduction and Summary of Findings}

Disabled students have rarely been considered in the Widening Participation literature. Definitional incompatibilities, inconsistencies between different datasets and small sample sizes explain at least part of this gap in the evidence base.

In this paper we seek to address this gap in the literature. The main purpose of this paper is to bring together in one place various statistics and facts that are available from a range of sources $^{1}$, and to provide as comprehensive a picture as possible about disabled students and higher education. We also present the findings of some new analysis that provides estimates of participation rates of disabled people (i.e. whether the number of disabled students in Higher Education (HE) is representative of the number of disabled people in the general population).

We take a "story-line" approach to this report, and look at the position of disabled people prior to, into, through, and out of HE and into the labour market. Consequently, Section 2 looks at the prior attainment and post-16 participation in education of young people. We also present some evidence describing attitudes towards HE of disabled people and people without disabilities. Section 3 documents how the proportion of applicants and accepted applicants who declare a disability has changed over time, and in Section 4 we do the same for the student population. In section 4, we also present some estimates of the HE participation rates of disabled young people, and the important role of prior educational attainment. Section 5 delves a little deeper into the characteristics of disabled HE students (in terms of their entry qualifications, gender, type of disability, mode, level and subject of study). Section 6 deals with student finance issues and in Section 7 we discuss the attainment of disabled HE students, both in terms of their non-continuation rates and the class of degree attained. Finally, Sections 8 and 9 look at the student experience and the immediate labour market outcomes of graduates, respectively.

Our main findings are as follows:

- At age 16, disabled people tend to have lower GCSE attainment than those without disabilites. They are also less likely to be studying for Level 3 qualifications (including A Levels) and, at ages 18 and 19, less likely to have attained such qualifications.

- We find that the proportions of applicants, accepted applicants and students enrolled in HE who declare a disability or are in receipt of Disabled Students' Allowances (DSAs) have increased over time. It is difficult to say, however, whether this is due to more students declaring / institutions recording a disability, or to an actual increase in the number of disabled students in HE.

- Estimates of young participation rates suggest that disabled people are considerably less likely to be in HE by the age of 19 than people without disabilities - although our analysis suggests that this closely reflects lower attainment at GCSE and A Level.

- $\quad$ Disabled HE students tend to have lower qualifications on entry than those without disabilities, and they are more likely to have entered HE through non-traditional routes. Their age upon entry tends to be higher.

\footnotetext{
${ }^{1}$ We use data from a range of sources including the Youth Cohort Study (YCS), the Universities and Colleges' Admissions Service (UCAS), the Higher Education Statistics Agency (HESA), the Student Income and Expenditure Survey (SIES), the National Pupil Database (NPD) matched to HESA records, and, the Labour Force Survey (LFS). The scope and limitations of each dataset are detailed in Annex 1.
} 
- Undergraduate (compared to postgraduate), male (compared to female) and full-time (compared to part-time) students are more likely to report a disability.

- $\quad$ Disabled students are slightly less likely to attain a good degree (first or upper second class) than those who do not report a disability, and there is evidence to suggest that this persists even after controlling for a range of other factors.

- By contrast, non-continuation rates are slightly lower for students reporting receipt of DSA than for other students - although we have no separate estimates for those reporting a disability but not receipt of DSA.

- While in HE students in receipt of DSA have slightly higher income and expenditure than other students. The higher income is accounted for by DSA and higher contributions from family and friends. The higher expenditure is due to higher living, housing and participation costs.

- Disabled students tend to be slightly less positive about the quality of their course, even after controlling for a range of other factors.

- The labour market outcomes for disabled graduates appear to be slightly worse than for those without disabilities. However differences between those with different types of disability appear to be more substantial. 


\section{Prior Attainment and Attitudes towards Higher Education}

This section presents information on the participation, attainment and aspirations of disabled young people prior to HE. From previous research, we know that prior attainment is strongly correlated with participation in $\mathrm{HE}$ and can explain much of the differences in participation observed between different groups of students. ${ }^{2}$ Indeed, in Section 4, we shall show how differences in participation rates between those with and without disabilities appear to be closely related to differences in prior attainment.

The evidence presented in this section draws primarily on analysis of the Youth Cohort Study (YCS). Most results are based on Cohorts 10,11, and, $12^{3}$ (i.e. on students aged 16 in 1999/00, 2001/02 and 2003/04 respectively). Generally the patterns observed are similar within each cohorts and we advise against reading too much into trends over time due to the small numbers of disabled people responding to each sweep of the survey (see annex).

We find that GCSE attainment for disabled young people is lower than for those without disabilities, and that disabled people are less likely to be studying for Level 3 qualifications at age 16 - although this gap disappears once we control for prior attainment. Level 3 attainment of disabled people is also lower than that for non-disabled people, although this does not seem to be the case among "high achieving" ( 5 or more GCSEs at grade $A^{*}-C$ ) disabled people. This high attaining group of people seems to have similar aspirations regarding HE whether or not they report a disability.

\section{GCSE Attainment}

Table 2.1 below shows that disabled students have lower GCSE attainment at the end of year 11.

Table 2.1: GCSE attainment by 16 year olds in 2003/04

\begin{tabular}{lcc}
\hline Proportion (\%) of students achieving: & With disability & $\begin{array}{c}\text { Without } \\
\text { disability }\end{array}$ \\
\hline 5 or more GCSEs $A^{*}-C$ & 37 & 53 \\
5 or more GCSEs $A^{*}-C$, including English and & 30 & 45 \\
Mathematics & 25 & 40 \\
\hline or more GCSEs $A^{*}-C$ & & \\
\hline
\end{tabular}

Source: YCS Cohort 12

\footnotetext{
${ }^{2}$ For example DIUS (2008).

${ }^{3}$ Occasionally we present the results of analysis of YCS cohort 13, which contains information on those aged 16 in 2006/07, however since we have not merged these results with those from the Longitudinal Study of Young People in England they are based on a smaller number of respondents and are less reliable as a consequence.
} 
Figure 2.1 below suggests that the attainment of 16-year olds who report a disability has not changed dramatically over time - although the uncertainties caused by sampling for the YCS mean that subtle changes over time are difficult to detect.

Figure 2.1: Proportion of 16 year olds attaining 5+ good GCSEs, 1999-2006

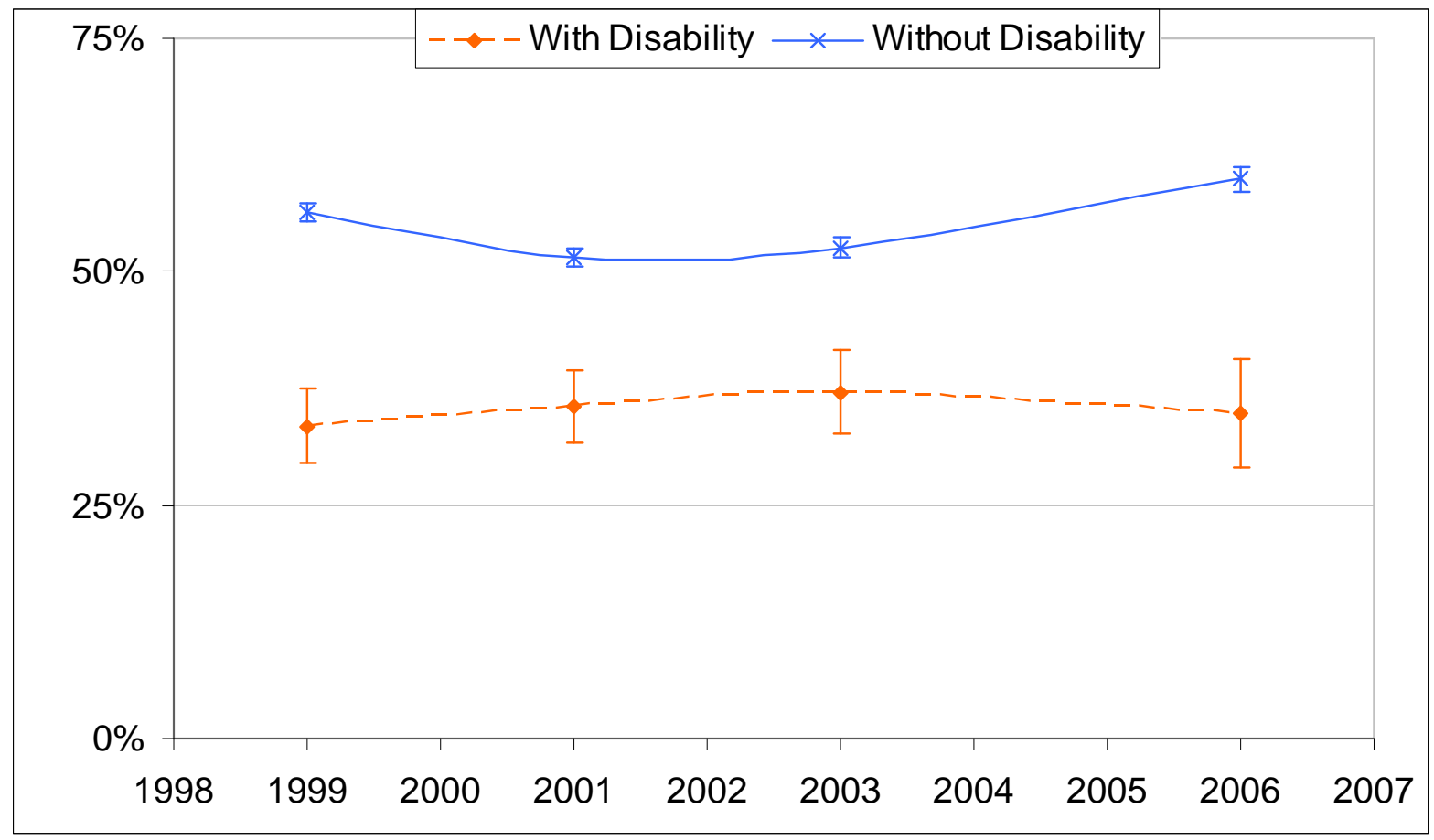

Source: YCS Cohorts 10, 11, 12 and 13. 


\section{Study at 16}

In 2003/04, disabled people were only slightly less likely than those without disabilities to be studying full-time at age $16(68 \%$ v. $72 \%)$. However, they were less likely to be studying for level 3 qualifications (42\% v. 53\%), and less likely to be studying for 2 or more A levels (32\% v. $43 \%$ ). As above these estimates are not precise enough to be able to identify any trends over time.

Figure 2.2: Proportion studying for level 3 qualifications at age 16, 1999-2003

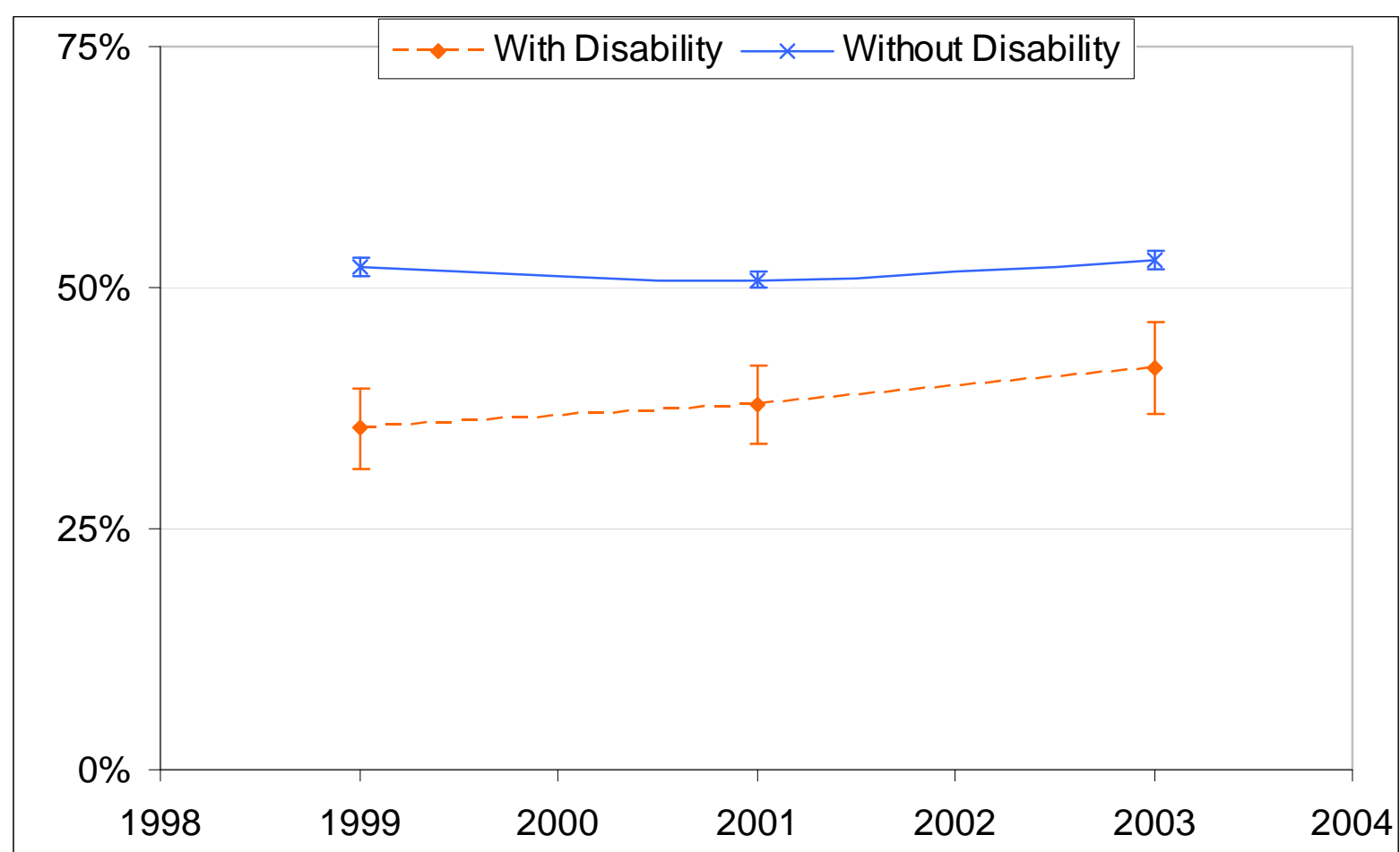

Source: YCS Cohorts 10,11 and $12^{4}$.

When we look only at those students with five or more good GCSEs, we find that the gap in the proportion of students studying for 2 or more A levels disappears (80\% for both groups). This suggests that lower GCSE attainment (figure 2.1), leads to lower study aims at age 16 (figure 2.2).

\footnotetext{
${ }^{4}$ For YCS cohort 13 changes to the survey methodology and the definitions of variables make the comparability of the results unclear.
} 


\section{Level 3 Attainment}

Since fewer disabled people are studying towards Level 3 qualifications at ages 16 and 17, it is unsurprising that, when looking at Level 3 attainment at age 19 (Figure 2.3), we find that only $39 \%$ of disabled people have attained Level 3, compared to $53 \%$ of those without disabilities.

Figure 2.3: Proportion (\%) holding level 2 (L2) and level 3 (L3) qualifications at age 19

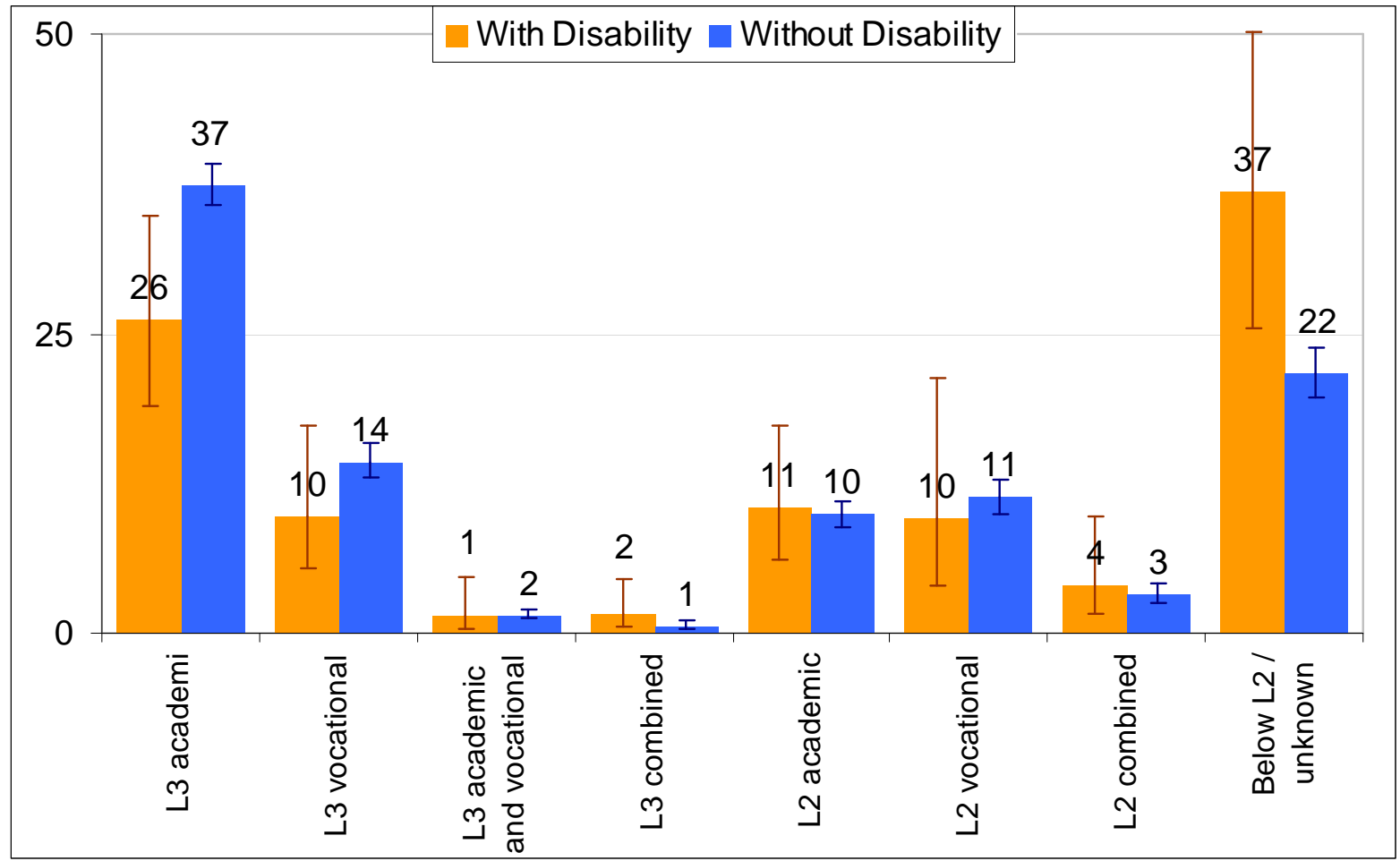

Source: YCS Cohort 12

Narrowing the focus to A level attainment, we find a similar pattern. Figure 2.4 shows that disabled people are less likely to attain A levels than people without disabilities, and that those who do are likely to attain fewer A levels than those without disabilities. $20 \%$ of disabled people attain 3 or more A levels compared to $29 \%$ of people without disabilities. Figure 2.5 shows that GCSE attainment is a very strong factor in explaining this observation. The relationship between GCSE attainment and A level attainment is similar when comparing those with and without disabilities. 
Figure 2.4: Proportion (\%) attaining different numbers of A levels by age 18

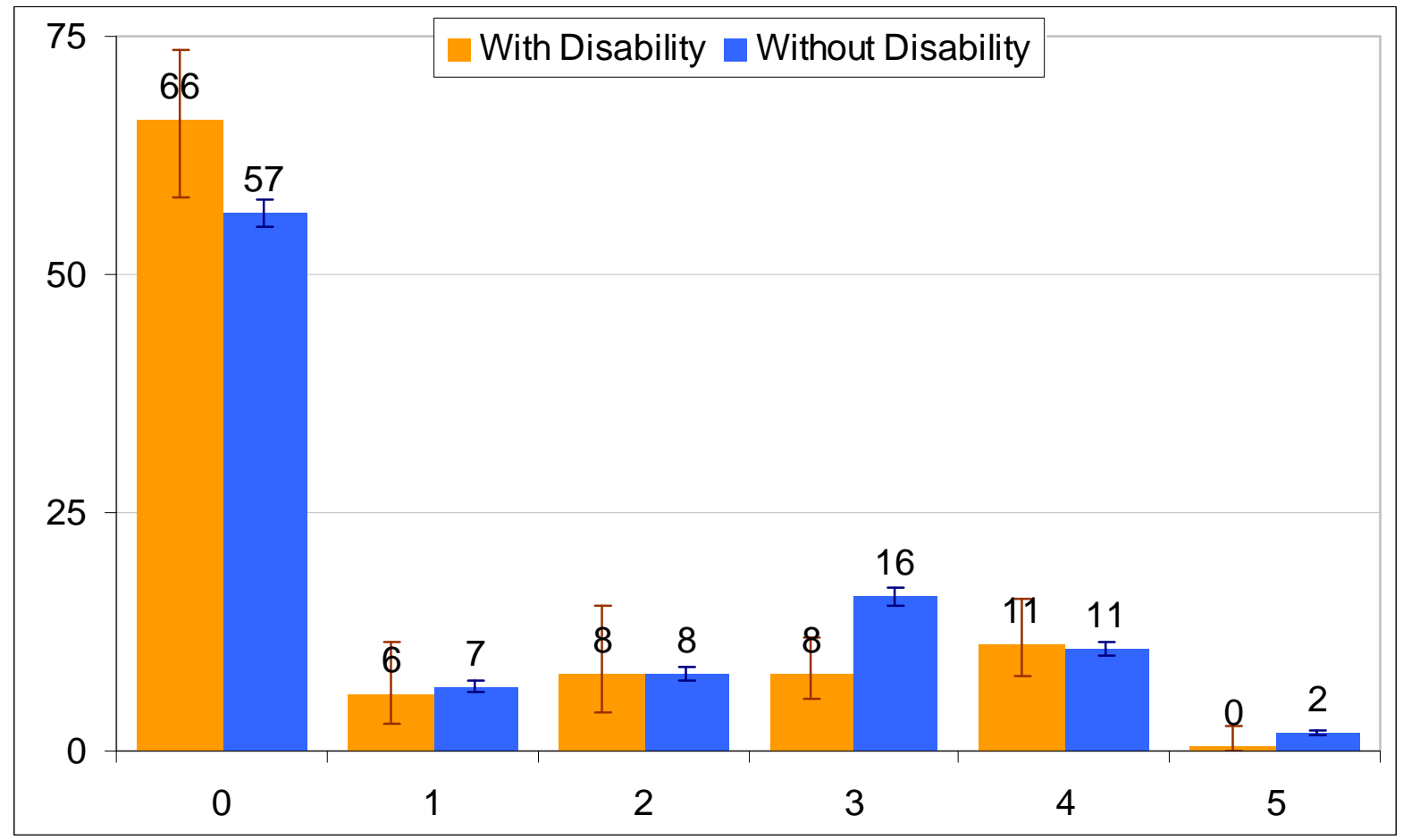

Source: YCS Cohort 12

Figure 2.5: Relationship between GCSE attainment and A level attainment for those attaining $A$ levels by age 19/20 in 2006/07

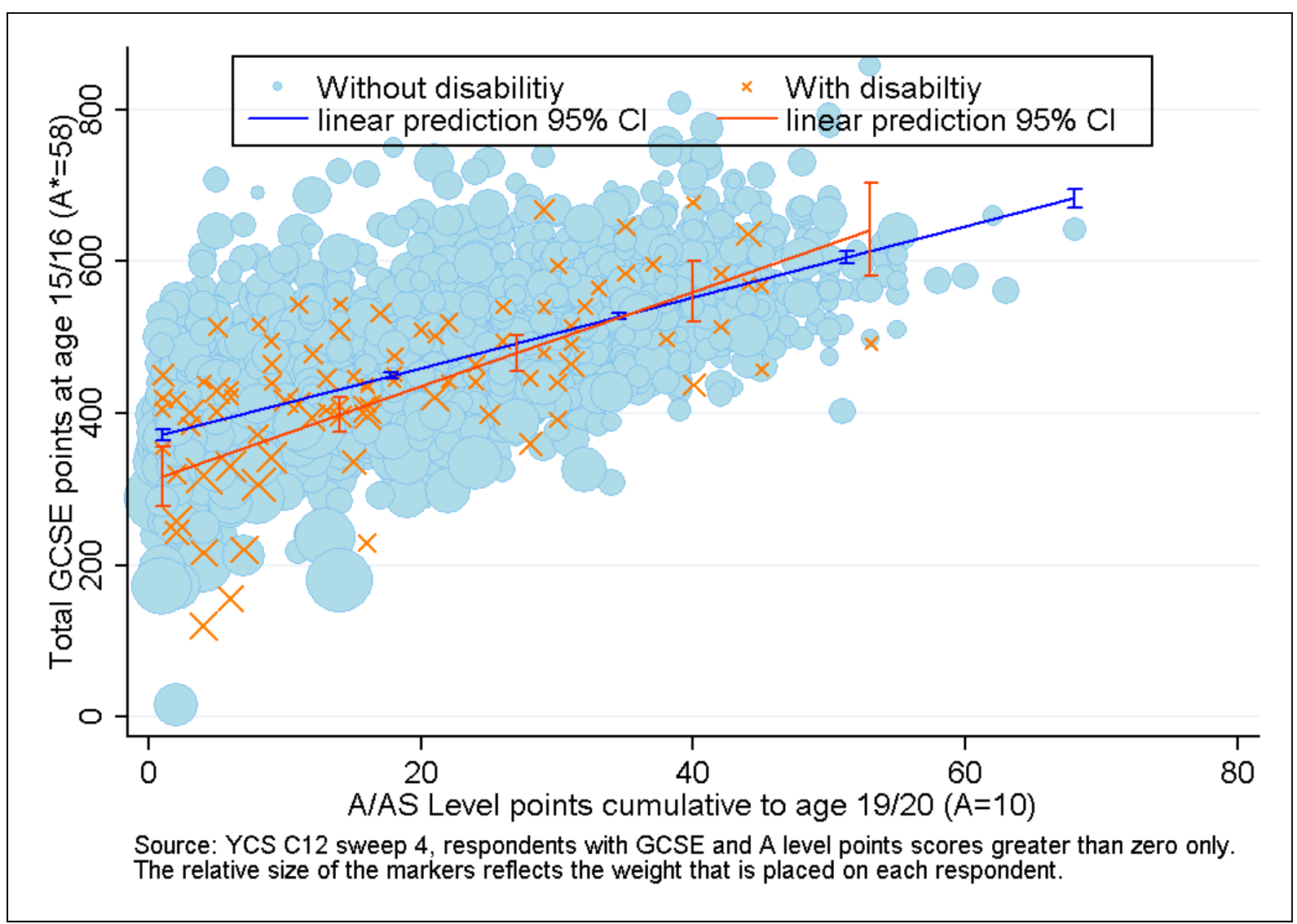




\section{Attitudes towards HE}

Although attainment at GCSE and A level contributes a great deal to the explanation of participation in $\mathrm{HE}$, attitudes and expectations can also play an important role. At age 17, the "high achievers" (i.e. those with five or more good GCSEs) in the YCS are asked about their attitudes towards HE. We can break this down by whether or not students reported a disability (at age 16), but the sample sizes are very small: only 57 out of 2,107 (unweighted) cases reported having a disability at 16 - so extreme caution is advised when interpreting the results that follow.

When asked whether or not they would apply for an HE course either this or next year, $78 \%$ (45 out of 57 unweighted cases) of 17 year olds with a disability and five good GCSEs replied in the affirmative. This is only slightly lower than the proportion of 17 year olds without disabilities who said they would apply (82\%). This similarity is not entirely surprising since we are, in effect, controlling for prior attainment/ability by selecting only high achievers.

Unfortunately, the sample size is too small to be able to draw significant conclusions about the reasons given by disabled people for or against applying to HE. 


\section{Applicants and Accepted Applicants}

In this section, we turn our attention to applicants to HE and accepted applicants. Most of what follows is based on the annual data sets made available by the Universities and Colleges Admissions Service (UCAS).

We find that the proportion of applicants and accepted applicants who declare a disability has increased over time. However, it is difficult to say whether this is due to more students declaring a disability, or to an actual increase in the number of disabled students applying / being accepted to HE.

In 2007, 25,970 students who applied through UCAS declared a disability, 20,452 of whom were accepted $-5.7 \%$ and $5.6 \%$ of the respective totals. Figure 3.1 below shows that the proportion of applicants who declared a disability on their UCAS application form has gradually increased over the past 7 years.

Figure 3.1: Proportion of applicants and accepted applicants declaring a disability (UK-domiciled, full-time undergraduate courses)

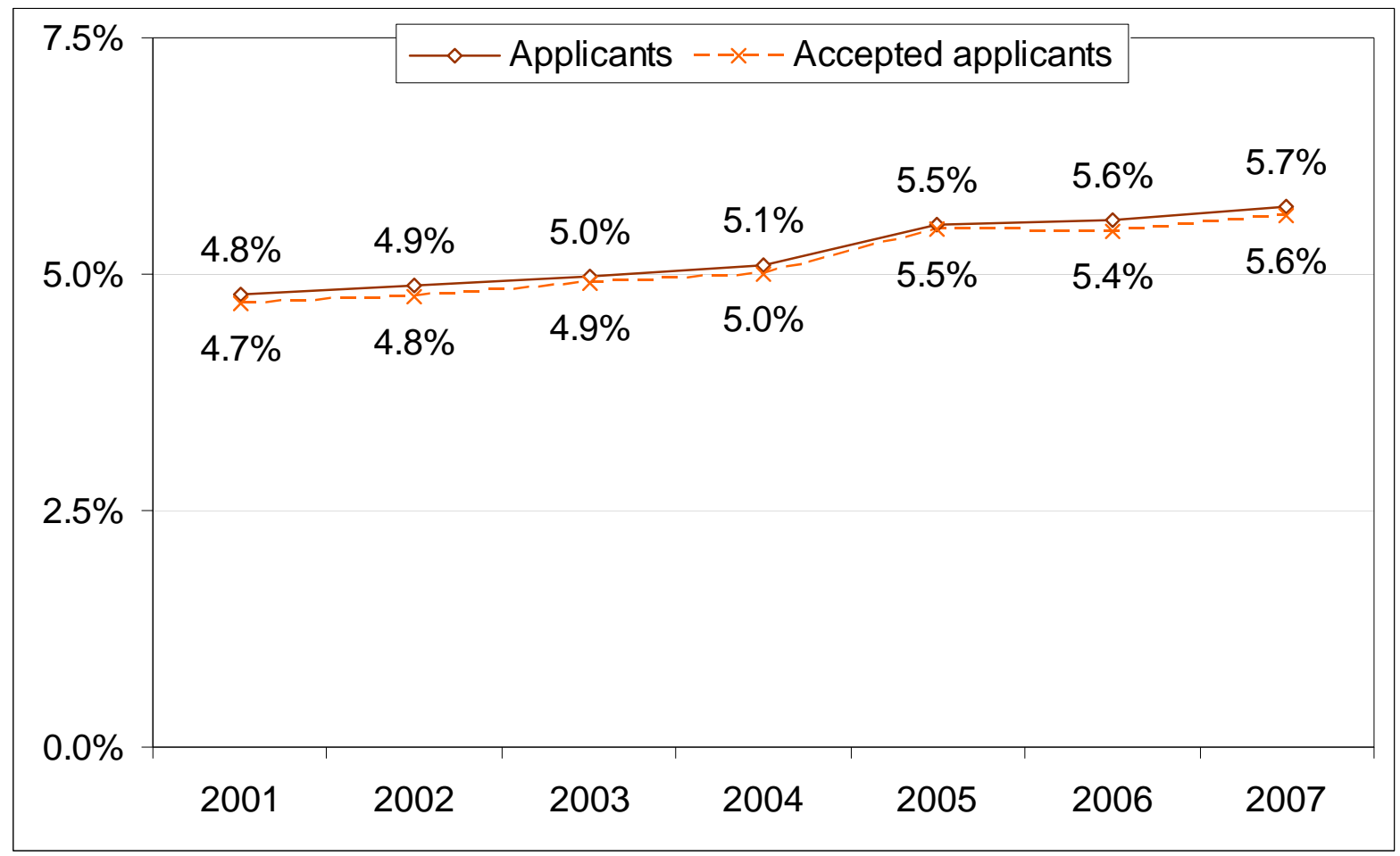

Source: UCAS Annual Data Sets

The proportion of applicants and accepted applicants who declare a disability has increased over time, by almost 1 percentage point between 2001 and $2007^{5}$ (i.e. an increase of around 19\%). The use of italics here is important: the observed increase does not necessarily mean that more disabled students are now applying/being accepted to higher education.

\footnotetext{
${ }^{5}$ There is no substantial difference in terms of the proportion of disabled people between applicants and accepted applicants.
} 
The observed pattern could be explained by a combination of factors which affect:

- Students' incentives to:

o apply for and take up benefits;

o seek diagnosis of impairment;

o disclose an impairment to the institution/UCAS;

- And Institutions' incentives to:

o collect information;

o recruit disabled students;

- facilitate / encourage diagnosis of disability.

In the past applicants may have been more reluctant to disclose a disability for fear that it would disadvantage them somehow or because they saw no reason to inform UCAS. A number of changes have been made to the DSA regulations over time which have opened it up to a greater number of people, including: removal of the means-testing of DSA in 1998/99 and the extension of DSA support to part-time students ${ }^{6}$ and postgraduate students along with distance learners and Open University students in 2000/01. In 2005/06, DSA support was extended to students undertaking full-time undergraduate courses by distance learning.

Similarly, changes that the Higher Education Funding Council for England (HEFCE) brought to the funding of provision for disabled students in 2000/01 (where funding is now based on the number of students in receipt of the DSA, whereas previously HEFCE had taken a project-based approach), have probably provided an incentive for institutions to set up processes to collect this information in a more systematic manner. The publication of Performance Indicators, providing institutional level information about the proportion of students in receipt of DSA may also have played a role.

Significant changes in legislation have also improved the rights of disabled people including those of disabled students.

\footnotetext{
${ }^{6}$ For courses that last at least one-year and take no more than twice the time of the equivalent full-time course.
} 


\section{Participation in Higher Education}

So far we have discussed what happens prior to HE (including the process of applying and being accepted to HE). In this section, we use HESA data to look at those who actually end up in HE and the proportion of these that report a disability. As in the case of the UCAS data, we find that the number of students who report a disability and who are in receipt of Disabled Students' Allowances (DSAs) has been steadily increasing over time.

The second part of this section focuses on the crucial issue of participation rates: i.e. the extent to which disabled people are over- or under-represented in Higher Education. We argue that the derivation of participation rates for disabled people is marred with difficulties. However, we present some tentative estimates of participation rates for young people using three different data sources with different definitions of disability. This suggests that wide gaps in participation exist between disabled and non-disabled people. However, our analysis also suggests that much of this gap is related to prior attainment.

\section{Proportion of disabled students in HE}

In 2006/07, there were 31,065 (8\%) UK-domiciled, first year, full-time undergraduates who had declared a disability on the HESA record. This proportion is slightly higher than that found in UCAS data presented above. Much of this difference may relate to definitional differences in the populations covered, but a report by the Snowdon Award Scheme ${ }^{7}$ suggested that part of the discrepancy may be due to the fact that some individuals are unable to get a diagnosis before entering HE or have not realised that they have a disability.

Figure 4.1 below shows how the number of students who have been reporting a disability and who have been reporting receipt of DSAs has been steadily increasing over time.

Figure 4.1: Proportion of UK-domiciled, full-time undergraduate students by disability status

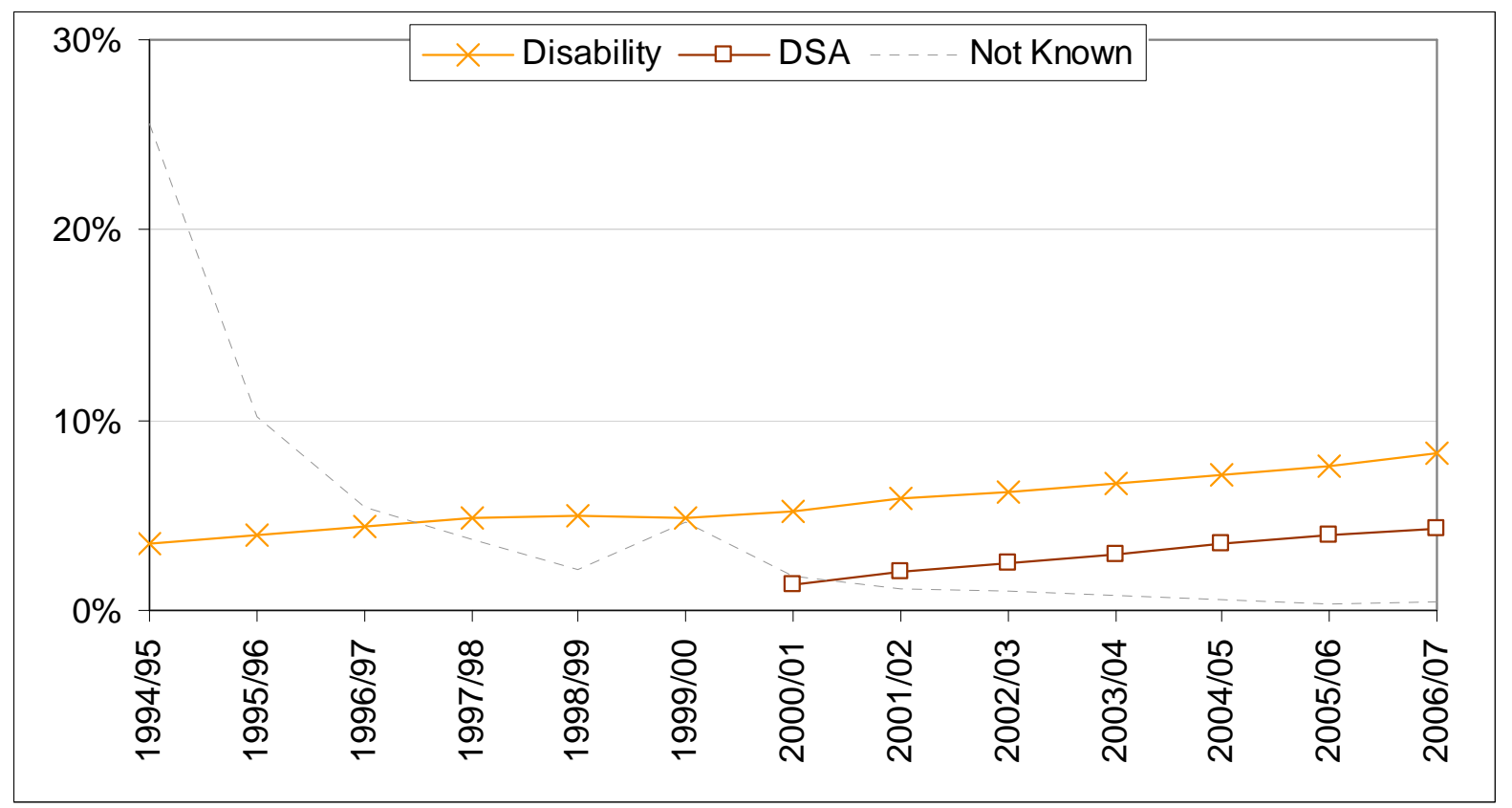

Source: HESA Students and Qualifiers Data Tables

\footnotetext{
${ }^{7}$ Tozer (2006, p 13). But this result is based on a sample of only 31 students.
} 
Receipt of DSA is an alternative measure contained in the HESA data that is sometimes considered more reliable than the other questions on disability, although it has a different implicit definition of disability based on the eligibility requirements for the allowance and is still ultimately based on self-reported information. The DSA figures are lower which reflects the eligibility criteria but exhibit a similar increase since 2000/01.

As with the trends in the number of applicants and accepted applicants discussed in Section 3 , it is not clear whether these increases reflect an actual increase in the number of disabled students in HE - or whether it is a result of students increasingly reporting a disability and/or institutions recording it.

Figure 4.1 also includes the proportion of students whose disability status is unknown. As the graph shows, this has dropped significantly over time, providing at least some indirect evidence of the effort that institutions have made to improve data collection - most likely following attempts to comply with formalised legal obligations, and, changes to the HEFCE funding system.

\section{The HE Participation Rate of Disabled People}

The trends and patterns observed above provide an interesting picture of the population within HE. However, they tell us nothing about changes in the underlying population of disabled people; thus we cannot conclude that disabled people are either under- or overrepresented in $\mathrm{HE}$, nor whether there have been any changes in their participation rates over time.

Ramsden (2005) concluded that attempts to calculate formal participation rates ${ }^{8}$ for disabled people were compromised by 4 factors:

- There is no generally recognised definition of disability, and also no general taxonomy of subsets of disability.

- Disability is essentially self-assessed.

- The coding frames which are used in national statistics and higher education statistics are significantly at variance.

- And even within the Higher Education constituency, there is no consistency of definition as between the HEls and the Further Education Colleges which provide Higher Education courses.

This is discussed in more detail in the appendix. However, to briefly illustrate the third point made by Ramsden (that there is no immediate prospect of aligning the numerators and the denominators of a participation index for disability), it is worth considering some measures of the prevalence of disability in the general population. As table 4.1 below illustrates, estimates of the prevalence of disability in the general population vary widely, not only depending upon the measure/definition used, but even across the same measure depending upon the age group looked at.

\footnotetext{
${ }^{8}$ Such as the higher education participation rate, e.g. DIUS (2008)
} 
Table 4.1: Comparison of a range of prevalence rates (\%) of disability, by age group

\begin{tabular}{|c|c|c|c|c|}
\hline Data source: & LFS $^{9}$ & LFS & LFS & FRS $^{10}$ \\
\hline Measure: & WLD $^{11}$ & DDAc $^{12}$ & long-term disabilities $^{13}$ & LLSI $^{14}$ \\
\hline $16-19$ & 6.6 & 5.5 & 8.6 & 6.8 \\
\hline $20-24$ & 9.0 & 7.9 & 11.4 & 7.4 \\
\hline $25-29$ & 9.9 & 8.1 & 12.0 & 9.2 \\
\hline $30-34$ & 11.4 & 9.6 & 13.5 & 9.1 \\
\hline $35-39$ & 12.6 & 11.5 & 15.3 & 12.2 \\
\hline $40-44$ & 17.0 & 15.1 & 20.0 & 16.1 \\
\hline $45-49$ & 20.3 & 19.3 & 23.9 & 18.7 \\
\hline $50-54$ & 25.2 & 23.9 & 29.4 & 22.9 \\
\hline $55-59$ & 30.9 & 29.2 & 35.4 & 29.2 \\
\hline $60-64$ & 43.0 & 37.2 & 47.4 & 41.1 \\
\hline Overall prevalence & 18.3 & 16.7 & 21.4 & 16.7 \\
\hline $\begin{array}{l}\text { Age-adjusted } \\
\text { prevalence }^{15}\end{array}$ & 17.0 & 15.4 & 20.0 & 15.7 \\
\hline
\end{tabular}

However, a number of datasets allow us to draw some tentative conclusions about the participation rate of disabled people, and its relationship with prior attainment. These are: the YCS, the Labour Force Survey (LFS) and the recently matched National Pupil Database (NPD) and HESA dataset. All three sources suggest that, at least for young people, the participation rates of disabled people are markedly below those of non-disabled people. However, the analysis also suggests that these gaps in participation are closely related to differences in prior attainment.

Using the YCS we estimate that, by age 19, the proportion of disabled people that have participated in HE courses is around $30 \%$, as opposed to $45 \%$ of those without disabilities. Repeating this analysis for those who attained 5 or more GCSEs at grade $A^{*}-C$ shows negligible and statistically insignificant differences in participation rates - although the estimate of the participation rate of disabled people with such qualifications is not very precise owing to the small sample size.

\footnotetext{
${ }^{9}$ LFS: Labour Force Survey

${ }^{10}$ FRS: Family Resources Survey

${ }^{11}$ WLD: Work-Limiting Disability: the respondent's perception in her or his capacity for paid work, in either the kind or amount of work they could do, or both. At its core, the question is hypothetical in that it asks the respondents to consider work they might or could do. Respondents are also asked to judge if their work capacity is causally connected to an underlying health problem (rather than to other sorts of factors such as environmental or attitudinal barriers) and to assess if this problem is enduring.

${ }^{12}$ DDA: Disability Discrimination Act: this measure seeks to identify whether respondents have a disability covered by the 1995 Disability Discrimination Act (DDA). The DDA defines disability as a 'physical or mental impairment which has a substantial and long-term adverse effect on (a person's) ability to carry out normal day-today activities.'

${ }^{13}$ The Government's PSA target to increase the labour market participation of disabled people is based on the number of people who are long-term disabled. This includes people of working age covered by the DDA as well as those with a work-limiting disability (WLD).

${ }^{14}$ LLSI: the most well-known and widely used single-item survey instrument for assessing activity limitation is the self-reported limiting longstanding illness or disability question (LLSI). Variants of this question intend to capture the perceived disabling effects of chronic ill-health (morbidity) and physical and sensory impairment.

${ }^{15}$ These estimates have been adjusted for differences in the age-distribution of respondents in the various surveys being compared. The reference population used is the GB census 2001 gender and age distribution.
} 
Figure 4.2: HE participation rates by age 19 in 2002/03, 2004/05 and 2006/07

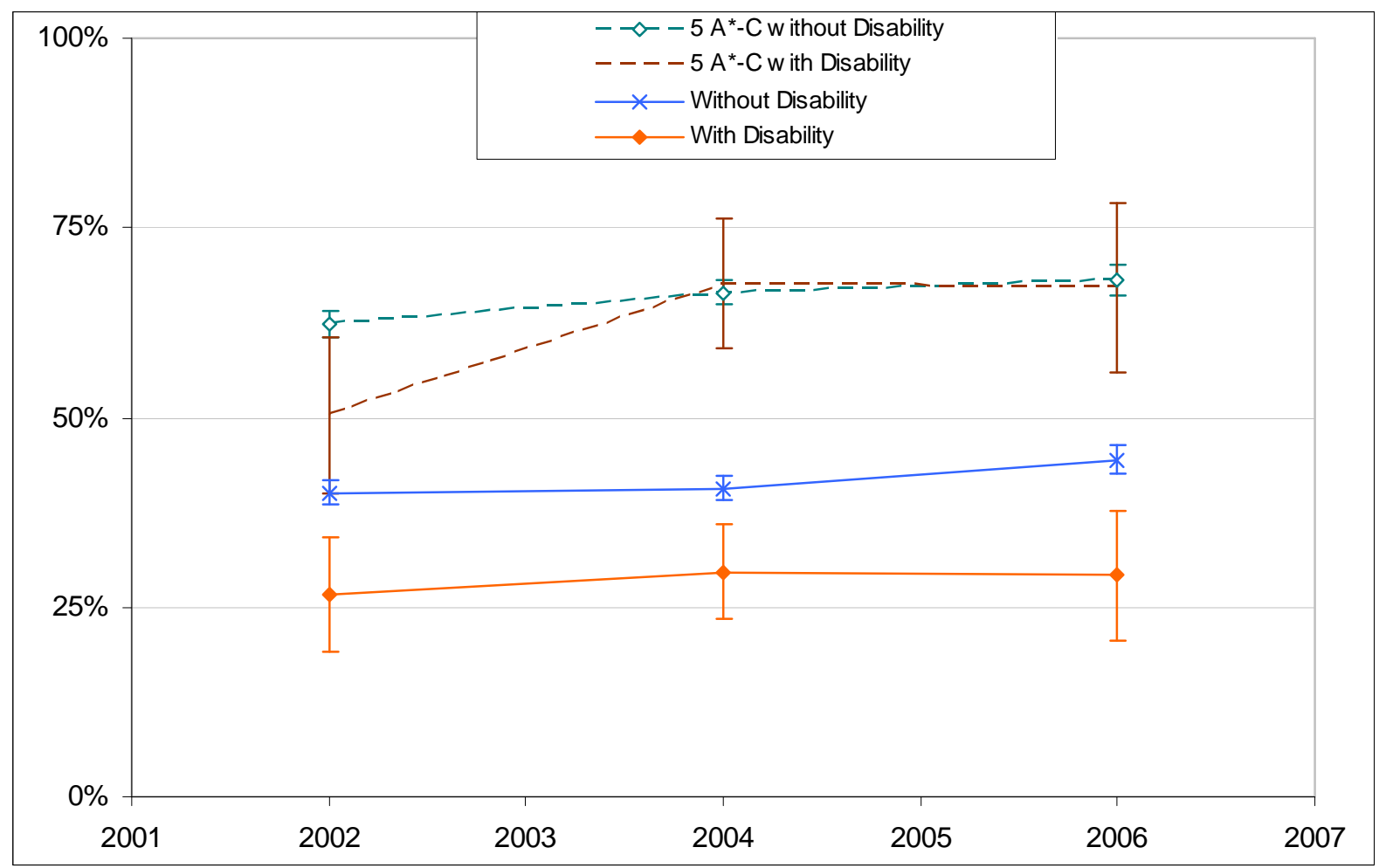

Source: YCS cohorts 10, 11, 12

We can also examine young participation using the LFS but we must pool several quarters together in order to obtain reasonable estimates. The estimates below are based on 10 quarters of LFS data from January-March 2006 to April-July 2008 relating to those living in England. ${ }^{16}$ Figure 4.3 shows the estimates of the proportion of young people with DDA disability whose current study aim is HE level.

\footnotetext{
${ }^{16}$ We have retained all responses from the first quarter in the sample and only responses from wave 1 of the survey for subsequent waves.
} 
Figure 4.3: Proportion (\%) studying towards a degree or higher level qualification by disability

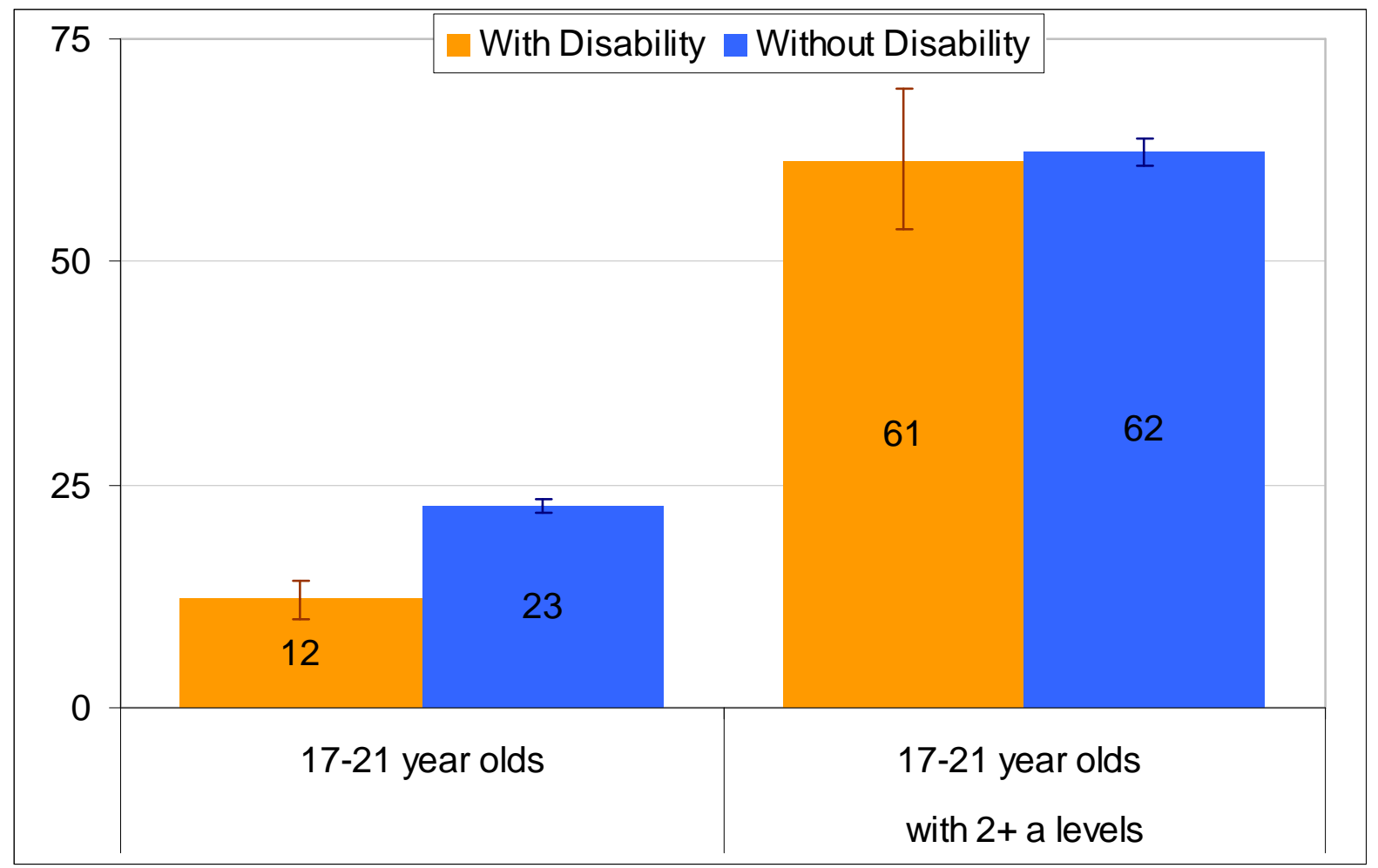

Source: LFS 2006-2008

It should be borne in mind that the LFS definition of disability used here ${ }^{17}$ is different from that used in the YCS so we would not expect the results regarding disabled people to be identical. Despite this we do see a similar gap between the participation rates of disabled young people and their peers without disabilities. For young people with two or more A levels we can detect no difference, although again the sample size is small enough to mean that the estimate of the participation rate of those holding $2+A$ levels with a disability is not very accurate $^{18}$.

The consistency of these results suggests that prior attainment might go a long way towards explaining the lower participation rate of disabled people. This might be expected given the size of the differences in level 3 study and attainment discussed in section 2.

A third source of information about participation of disabled young people is the National Pupil Database. Information about disability is not known, but the School Census does provide information about pupils with Special Educational Needs (SEN) ${ }^{19}$. For pupils aged 15 in 2001/02 information is also available regarding their HE participation at ages 18 and 19, since the HESA student record has been matched to the NPD. This makes it possible to calculate participation rates by age 19 and SEN status for the pupils aged 15 in English maintained schools in 2001/02.

\footnotetext{
${ }^{17}$ Here we have used the definition that is compatible with the Disability Discrimination Act.

1891 out of 210 young respondents with $2+$ A levels and a disability were studying for a degree.

${ }^{19}$ As SEN is based on conditions that impair the ability to access learning rather than activity in general there is no direct association with disabled people. Some people with SEN may have disabilities, but others will not; likewise many disabled people will not have SEN.
} 
Figure 4.4 shows that, as for disabled people, participation rates for young people seem to be much lower for those with SEN than those without SEN. However, looking only at those who have attained Level 3 through A levels at age 17, the difference is much smaller. One difference from the above results is that there is still a small difference after controlling for prior attainment. Much of this remaining difference is likely to relate to differential attainment within the $2+$ A level category ${ }^{20}$.

Figure 4.4: HE participation (\%) by age 19 (in 2005/06) by SEN status for English maintained school pupils

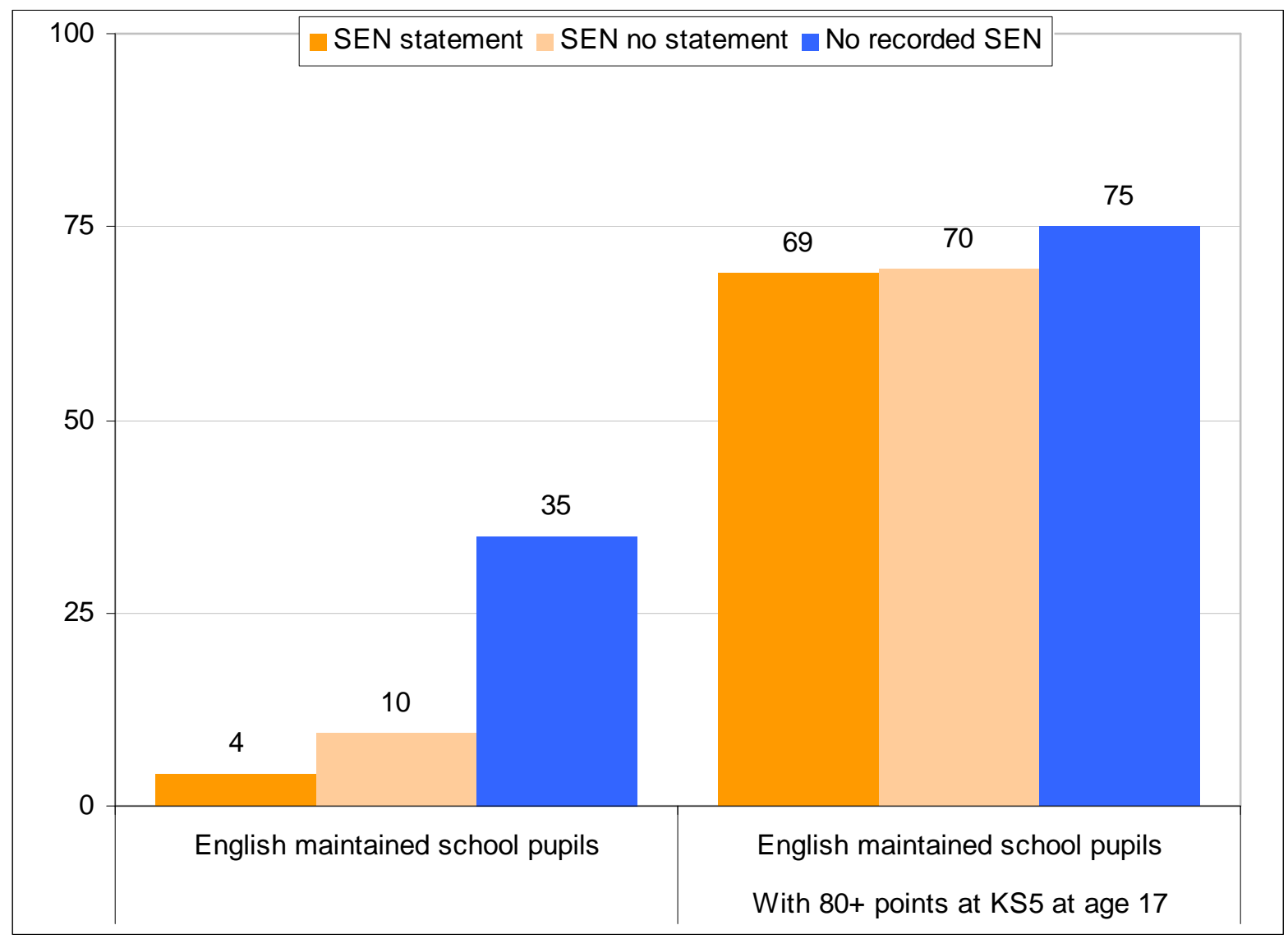

Source: matched NPD-HESA data

So, we have seen some evidence that the HE participation rate of disabled young people is lower than that of their non-disabled peers, and that the difference seems to relate to lower attainment at GCSE and A level. But we have not looked in detail at disabled older people. We say in table 4.1 that the incidence of disability appears to rise with age, meaning that any information about older age groups' HE participation is important. Table 4.3 confirms that disabled people in HE tend to be older than those without disabilities.

\footnotetext{
${ }^{20}$ See the logistic regression results in table A2 in the appendix shows that with more detailed controls for A level and GCSE attainment there is virtually no difference between SEN and non SEN participation rates.
} 
Table 4.3: Average age of UK domiciled students enrolled in the first year of full-time first degrees in 2006/07

Disability

Average age

No known disability

20

Autistic Spectrum Disorder

Dyslexia

21

Blind/are partially sighted

An unseen disability, e.g. diabetes, epilepsy, asthma

Multiple disabilities

Other

Information not sought

Deaf/have a hearing impairment

Not known

Personal care support

Mental health difficulties

Wheelchair user / have mobility difficulties

26

Total

20

Source HESA 2006/07

Due to the relatively low numbers of older HE participants in the LFS, it is not possible to look at those currently studying degrees using that data source. Instead we can look at the proportion of those with and without disabilities who have a degree. Figure 4.5 shows that a greater proportion of people without disabilities hold $\mathrm{HE}$ or higher level qualifications than disabled people. Again the difference is smaller for those holding two or more A Levels. It is worth bearing in mind that this information reflects participation in HE over a long period of time, during which the nature of HE has changed greatly, as has the support for disabled people in HE. So these estimates do not necessarily reflect issues facing older people today who may be considering acquiring higher education qualifications. 
Figure 4.5: Proportion (\%) of people holding an HE or other level 4 or higher qualification

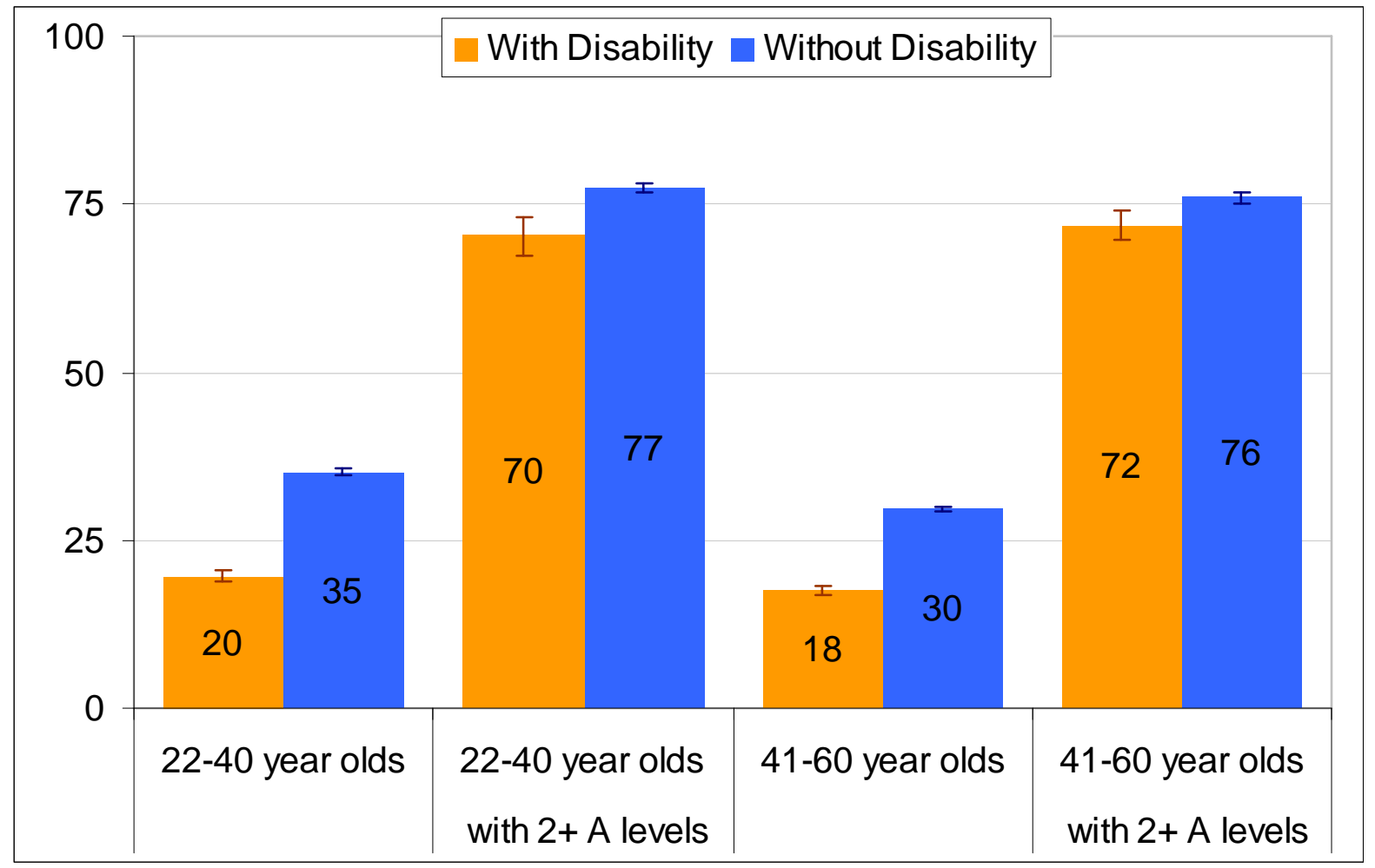

Source: LFS 2006-2008 


\section{Characteristics of Disabled People in Higher Education}

We now turn to examine the various characteristics of the HE student population covering: prior attainment, type of disability, mode of study, level of study, gender, and subject of study. We conclude: (i) that disabled students in HE tend to have lower entry qualifications than their counterparts who do not report disabilities, and that they are also more likely to have entered HE through non-traditional routes. (ii) That undergraduate (compared to postgraduate), male (compared to female) and full-time (compared to part-time) students are more likely to report disability. And finally: (iii) that "Creative arts and design" and "Agriculture and related subjects" had particularly high concentrations of students in receipt of DSA. Medicine, Mathematical Sciences, Languages and Law had particularly low concentrations of students in receipt of DSA.

\section{Prior Attainment of Students in HE}

Figure 5.1 looks at students with Level 3 qualifications and shows how the lowest tariff score ${ }^{21}$ bands tend to have a higher proportion of students reporting DSA receipt. This suggests that the disabled students in HE tend to be amongst those with lower entry qualifications, and reflects our finding in Section 2 that the prior attainment of disabled people is considerably lower than that of those without disabilities.

Figure 5.1: Proportion (\%) of full-time first degree UK domiciled students with GCE A or AS levels I Scottish Highers in receipt of DSA by entry qualifications, 2006/07

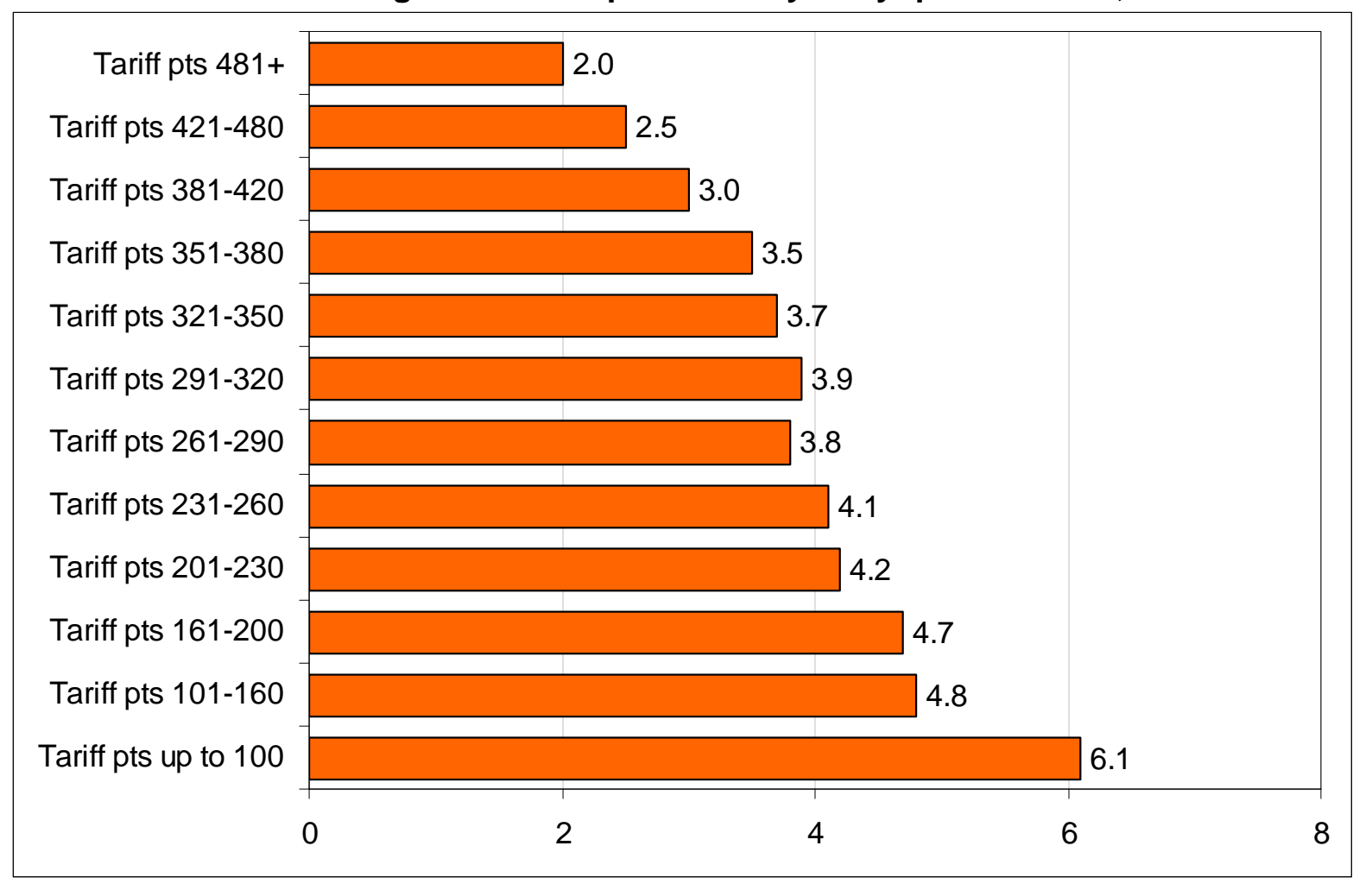

Source: HESA 2006/07 Performance Indicators

\footnotetext{
${ }^{21}$ The UCAS Tariff is a system used to aggregate a range of different types of entry qualifications into a single numerical scale and is used by many HE institutions to help regulate entry to their courses on the basis of academic attainment; see http://www.ucas.com/students/ucas tariff/
} 
When we look at those students who entered HE without academic Level 3 qualifications (Figure 5.2), we see that students who report to be in receipt of DSA tend to be more highly represented amongst those students who enter HE with a "Foundation or access course", with "BTEC, ONC, SCOTVEC or equivalent", or with no previous qualification at all.

Figure 5.2: Proportion (\%) of full-time first degree UK domiciled students in receipt of DSA by type of entry qualification , 2006/07

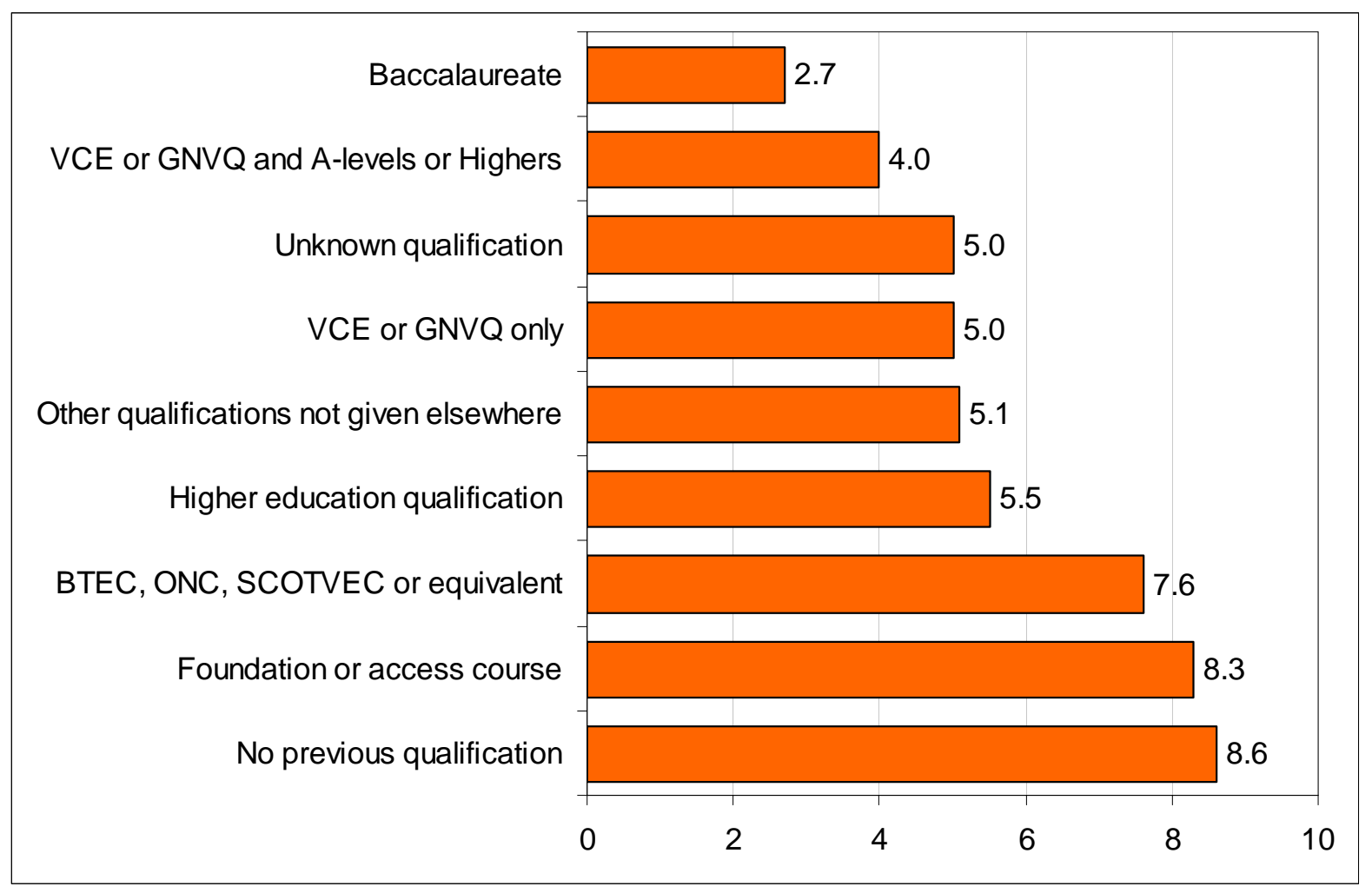

Source: HESA 2006/07 Performance Indicators

\section{Type of disability}

Figure 5.3 describes the type of disability reported by first year undergraduate students. The "unseen" and "dyslexia" categories together account for a large fraction (around 70\%) of the types of disability reported. Some disabilities, although still small as a proportion of the total, have seen very large increases over the period: the number of students reporting mental health problems has increased by more than ten times; the number of students reporting multiple disabilities have tripled; and there were over twice the number of wheelchair users / students with mobility difficulties in 2006/07 than there were in 1994/95. Many of these increases will reflect the sharp reduction in the number of students whose disability status is unknown.

The annex shows that the distribution for applicants and accepted applicants (UCAS data) follows a similar pattern, although the definitions of disability used by HESA and UCAS are not entirely comparable. 
Figure 5.3: Type of disability declared by first year UK domiciled full-time undergraduates

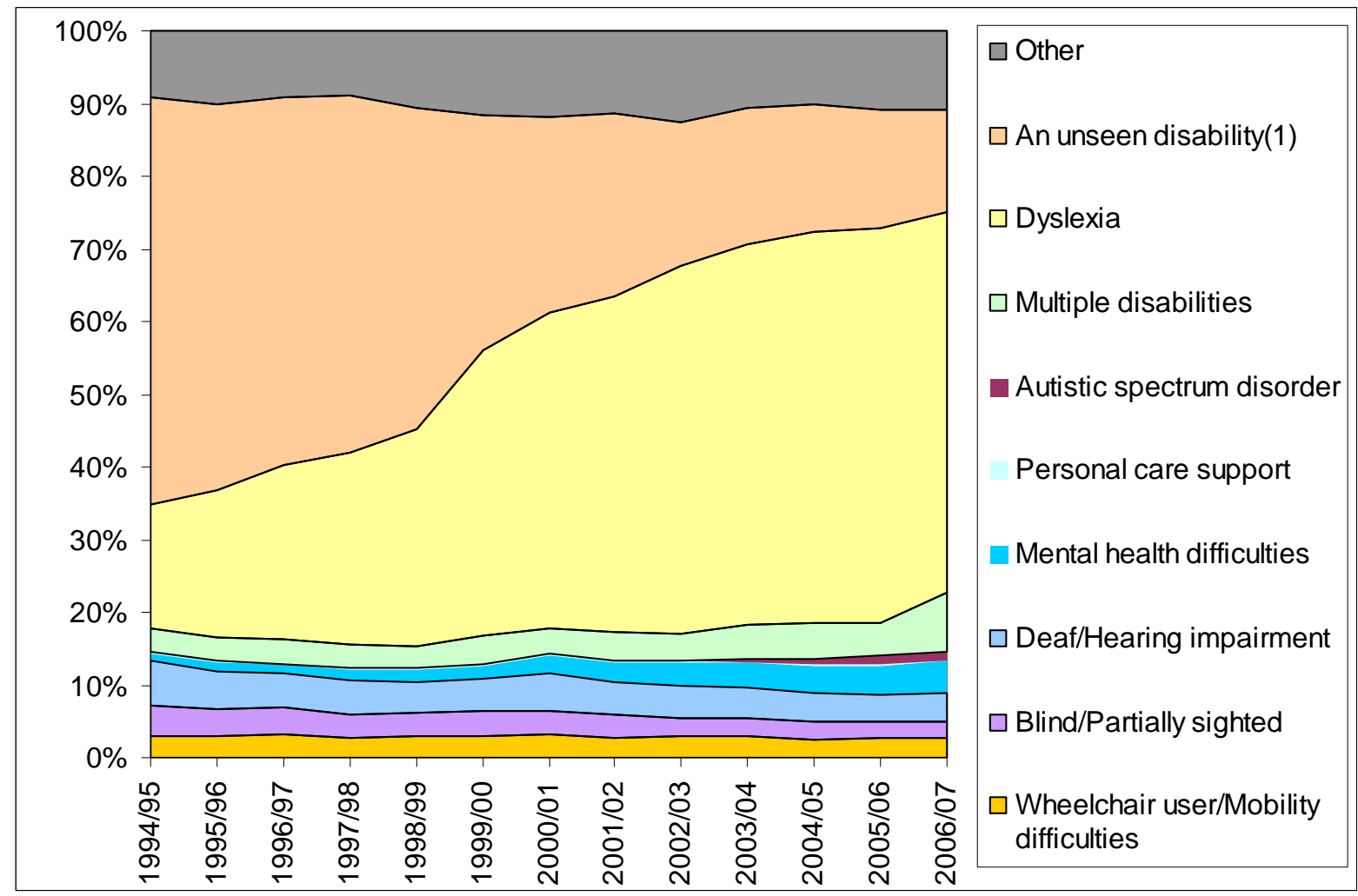

(1) An unseen disability means, for example, diabetes, epilepsy or asthma.

Source: HESA online statistics

\section{Mode of Study}

Of all undergraduates in 2006/07 (i.e. including both part and full-time), 129,110 (8\%) reported a disability. Only $6 \%$ of part-time undergraduates reported a disability, which suggests either (i) that disabled part-time students are less likely to declare a disability; or (ii) that disabled people are less likely to study part-time; or (iii) some combination of the two. Considering that part-time students generally receive a pro-rata DSA, but those studying less than $50 \%$ of full-time hours get lower rates for some DSAs ${ }^{22}$, this might partially explain why there seems to be a lower proportion of disabled students reporting a disability in the parttime population. However the non-medical helpers has been increased for part-time undergraduates in 2008/09.

Table 5.1 below further shows how the proportion of part-time undergraduates in receipt of DSA is lower than the proportion of full-time undergraduates in receipt of DSA - which mirrors the finding based on the proportion of students self-reporting a disability. This appears to support the interpretation that disabled people are less likely to study part-time.

\footnotetext{
${ }^{22}$ Although if their disability limits their intensity of study, they may receive additional discretionary support from the access to learning fund administered by HEls.
} 
Table 5.1: HE Performance Indicators, UK domiciled undergraduate students in receipt of DSA

\begin{tabular}{|c|c|c|c|c|c|c|c|}
\hline Year & $2000 / 1$ & $2001 / 2$ & $2002 / 3$ & $2003 / 4$ & $2004 / 5$ & $2005 / 6$ & $2006 / 7$ \\
\hline FT UG (000s) & 945 & 977 & 1,009 & 1,034 & 1,051 & 1,083 & 1,089 \\
\hline PT UG (000s) & 230 & 244 & 249 & 249 & 239 & 233 & 230 \\
\hline $\begin{array}{l}\% \text { of FT UG } \\
\text { with DSA }\end{array}$ & 1.4 & 2.0 & 2.5 & 3.0 & 3.5 & 4.0 & 4.3 \\
\hline $\begin{array}{l}\% \text { of PT UG } \\
\text { with DSA }\end{array}$ & 2.0 & 1.1 & 1.3 & 1.6 & 1.9 & 2.1 & 2.3 \\
\hline $\begin{array}{l}\text { Num FT UG } \\
\text { with DSA }\end{array}$ & 13,680 & 19,055 & 25,110 & 30,865 & 37,030 & 42,985 & 46,440 \\
\hline $\begin{array}{l}\text { Num PT UG } \\
\text { with DSA }\end{array}$ & 4,575 & 2,720 & 3,135 & 3,885 & 4,505 & 4,955 & 5,660 \\
\hline
\end{tabular}

Source: HESA / HEFCE performance indicators

\section{Postgraduate Study}

As for postgraduate students, 21,140 (6\%) declared a disability in $2006 / 07$. Again, this is lower than for full-time undergraduate students and, again, this could mean either (i) that disabled postgraduate students are less likely to declare a disability; (ii) that disabled people are less likely to pursue postgraduate studies; and/or (iii) the current postgraduate population is a reflection of a older cohorts of undergraduates that had fewer disabled students and so will naturally tend to lag behind increases in the undergraduate population. Hypotheses (i) and (ii) might be influenced in some way by the levels of DSA available for postgraduate students. In England the maximum postgraduate DSA was less than one third of the maximum undergraduate award. This makes postgraduate study relatively expensive compared to undergraduate study (for those eligible for DSA), and also reduces the incentive for postgraduate students who might have a disability to obtain a diagnosis and report their status to the institution. However, as with the part-time DSA, the level of allowance for postgraduate students has also been increased for 2008/09. 


\section{Gender}

Proportionately more male students declare a disability than female students (Figure 5.4). In $2006 / 07,9 \%$ of male first year undergraduates declared a disability compared to $8 \%$ of female first year undergraduates. The gap between the proportion of male and female undergraduates that declare a disability has grown over time, although it appears to have stabilised in recent years.

Figure 5.4: Proportion of male and female first year undergraduate students that report having a disability

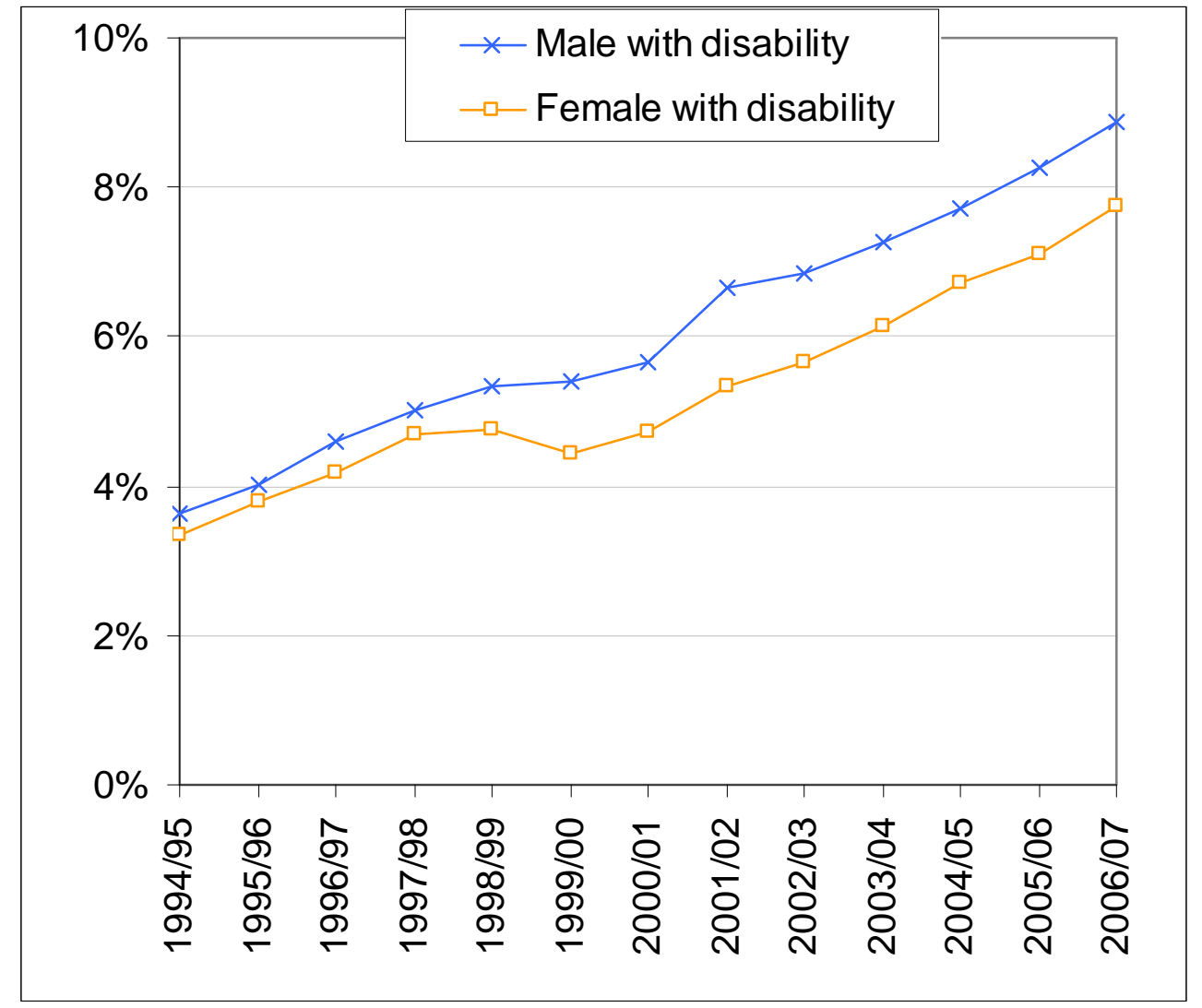

Source: HESA

\section{Subject choice}

Figure 5.5 below shows how, in 2006/07, "Creative arts and design" had particularly high concentrations of students in receipt of DSA. Other subjects that appear particularly popular with students receiving DSA are Agriculture, Social Studies and Architecture. Medicine, Mathematical Sciences, Languages and Law had particularly low concentrations of students in receipt of DSA. 
Figure 5.5: Proportion of students in receipt of DSA, by subject group, 2006/07

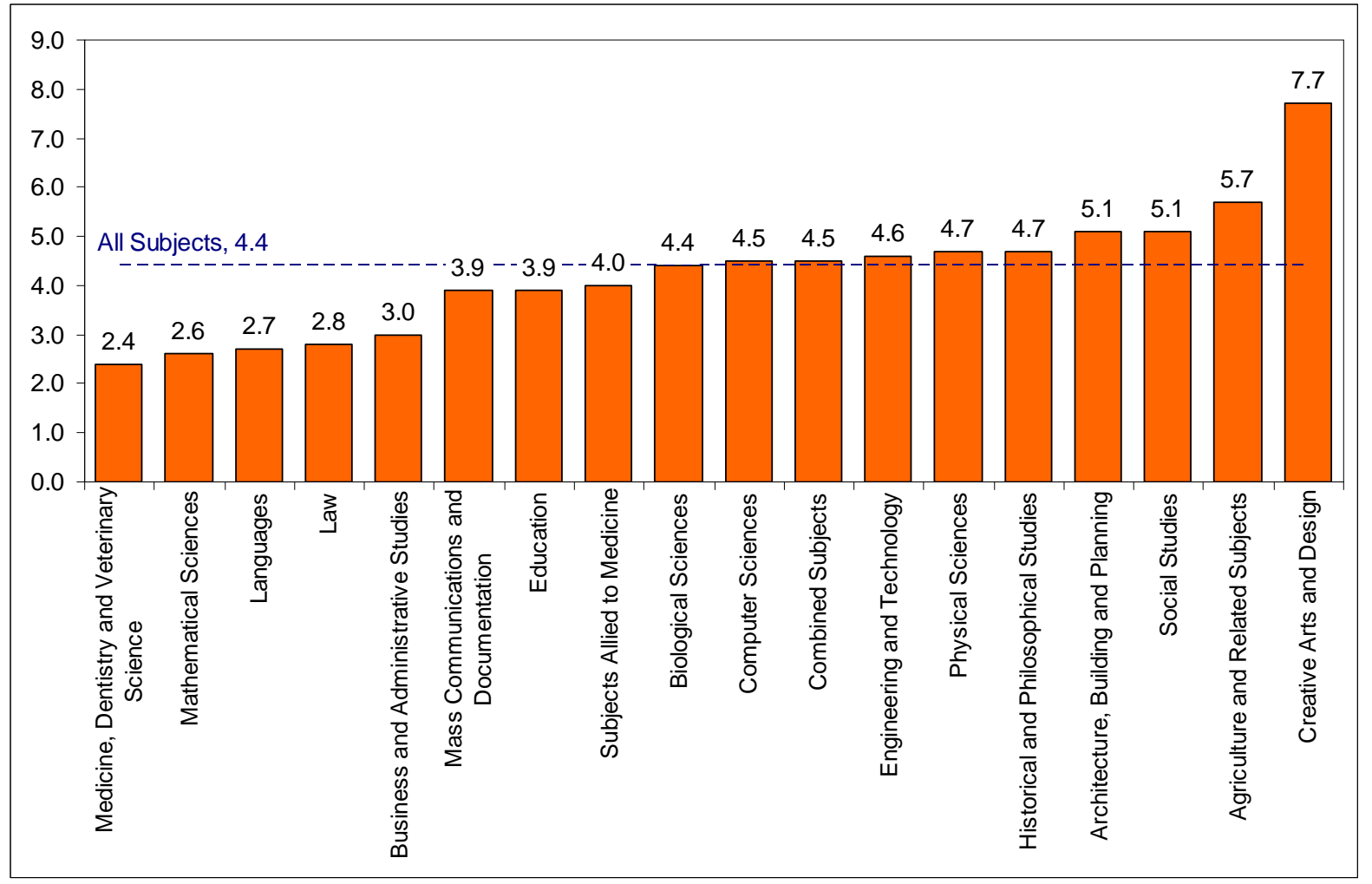

Source: HESA

Looking within types of disability we find that Creative Arts and Design are particularly popular with students with dyslexia (the most common disability) and those requiring personal care support. Although disabled students are much less likely to study Mathematics overall, $17 \%$ of students with autistic spectrum disorder study mathematical subjects, compared to $6 \%$ of students with no known disability. 


\section{Student Finance}

In this section, we examine information from HESA and the Student Income and Expenditure Survey (SIES) to look at the financial issues faced by disabled students, and how they differ from non-disabled students. We find that students in receipt of DSA have slightly higher income and expenditure than other students. The higher income is accounted for by DSA and higher contributions from family and friends. The higher expenditure is due to higher living, housing and participation costs. There does not appear to be any substantial difference in the amount of debt accumulated by disabled and students without disabilities.

\section{Warning on Small Sample Sizes}

The SIES dataset holds information for around 100 full time students who are in receipt of DSA. This is a small number, so results should be treated with some caution. There are insufficient numbers of part-time students to produce meaningful results. Results in the appendix show no overall differences between the basic characteristics of respondents in receipt of DSA and those not in receipt of DSA.

\section{Income}

According to SIES 2004/05, the mean level of income for full-time students was $£ 8,333$. Table 6.1 shows that the corresponding figure for those in receipt of DSA was $£ 10,493$. Most of this difference is accounted for by "other sources of student support" which includes DSA. Students in receipt of DSA also receive more income than average from family and friends (around $£ 500$ a year more). There is little difference arising from the other main sources of income.

Table 6.1: Total student income and main sources of income for all full time students and those in receipt of DSA (E)

\begin{tabular}{lcc}
\hline Sources of income & All FT & In receipt of DSA \\
\hline Main sources of student support & $£ 3,327$ & $£ 3,635$ \\
Other sources of student support & $£ 629$ & $£ 2,075$ \\
Income from paid work & $£ 1,821$ & $£ 1,671$ \\
Income from family and friends & $£ 2,104$ & $£ 2,641$ \\
Social Security Benefits & $£ 233$ & $£ 363$ \\
Other income & $£ 218$ & $£ 109$ \\
\hline Total Income & $£ 8,333$ & $£ \mathbf{1 0 , 4 9 3}$ \\
\hline
\end{tabular}

Source: SIES 2004/05

\section{Receipt of DSA by Disability}

Figure 6.1 shows HESA data on the proportion of UK domiciled first year full time first degree students in receipt of DSA by disability. Overall, $49 \%$ of students who report a disability are also in receipt of DSA. Those with "unseen" disabilities are least likely to be in receipt of DSA whereas those with autistic spectrum disorder, wheelchair / mobility difficulties, and, dyslexia are most likely to be in receipt of DSA. 
Figure 6.1: Proportion of students reporting disabilities who are in receipt of DSA, UK domiciles, full-time, first degree students, 2006/07

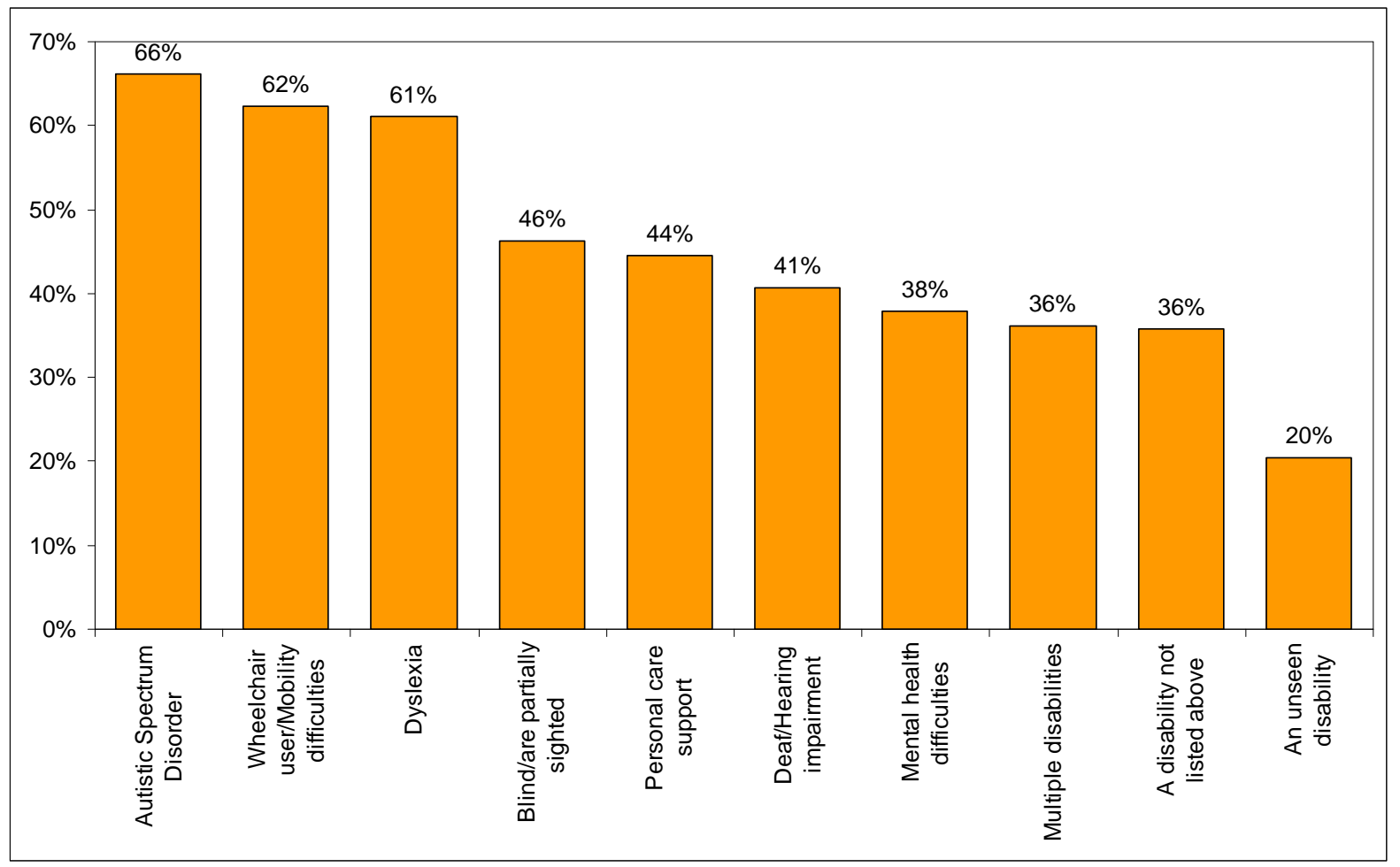

Source: HESA

\section{Expenditure}

SIES 2004/05 shows that the mean expenditure for full time students was $£ 10,273$. Table 6.2 shows that for those in receipt of DSA expenditure was slightly higher $(£ 11,320)$, but this is balanced out by their higher levels of income (see above). The largest difference came in living costs, although expenditure on housing and participation was also higher.

Table 6.2: Total student expenditure and main sources of expenditure for all full-time students and those in receipt of DSA

\begin{tabular}{lcc}
\hline Costs & All FT & In receipt of DSA \\
\hline Living Costs & $£ 5,870$ & $£ 6,519$ \\
Housing Costs & $£ 2,276$ & $£ 2,529$ \\
Participation Costs & $£ 1,980$ & $£ 2,110$ \\
Spending on Children & $£ 147$ & $£ 162$ \\
\hline Total Expenditure & $£ 10,273$ & $£ 11,320$
\end{tabular}

Source: SIES 2004/05 


\section{Views on Finance and Returns}

Students were asked whether their decisions prior to entering HE were affected by funding and financial support. Of all full-time students, $74 \%$ said they were not; for those in receipt of DSA the figure was broadly the same at $67 \%$. Similar views were found in responses to range of 'attitude' questions about experiences in $\mathrm{HE}$ and what they expected to get out of having a degree ${ }^{23}$. It should be pointed out, though, that these results are based on people in $\mathrm{HE}$, and therefore say nothing about the extent to which funding and financial support affected the decision of those who do NOT end up in HE.

${ }^{23}$ See annex figures $A 1.1$ and A1.2. 


\section{Non-Continuation and Degree Attainment}

This section examines the relative performance of disabled students in HE in terms of degree attainment and non-continuation rates. Again, most of the evidence presented here is based on HESA data. We find that students reporting a disability are only slightly less likely to attain a good degree (first or upper second) than students without disabilities, and that, perhaps surprisingly, non-continuation rates are slightly lower for students reporting receipt of DSA than for other students.

\section{Degree attainment}

Figure 7.1 shows the degree classification obtained by students with and without a disability. It shows that a slightly greater proportion of students with no disability (59\%) obtain a good degree than students with a disability (56\%). Clearly, this does not control for any other characteristics that may be associated with attainment (e.g. prior attainment, subject choice, etc.) but DfES (2007) multivariate analysis of HESA data suggests that disability, even after controlling for a range of other factors, still has a statistically significant and negative impact on degree attainment ${ }^{24}$. Attainment also differs slightly by disability, with $63 \%$ of students reporting a mental health difficulty attaining a good degree, compared to $55 \%$ of students with dyslexia and autistic spectrum disorder, and $52 \%$ of students with multiple disabilities.

\section{Figure 7.1: Distribution of degree attainment, by disability $\left(1^{\text {st }}\right.$ degree UK-domiciled} qualifiers, Full-Time and Part-Time, 2006/07)

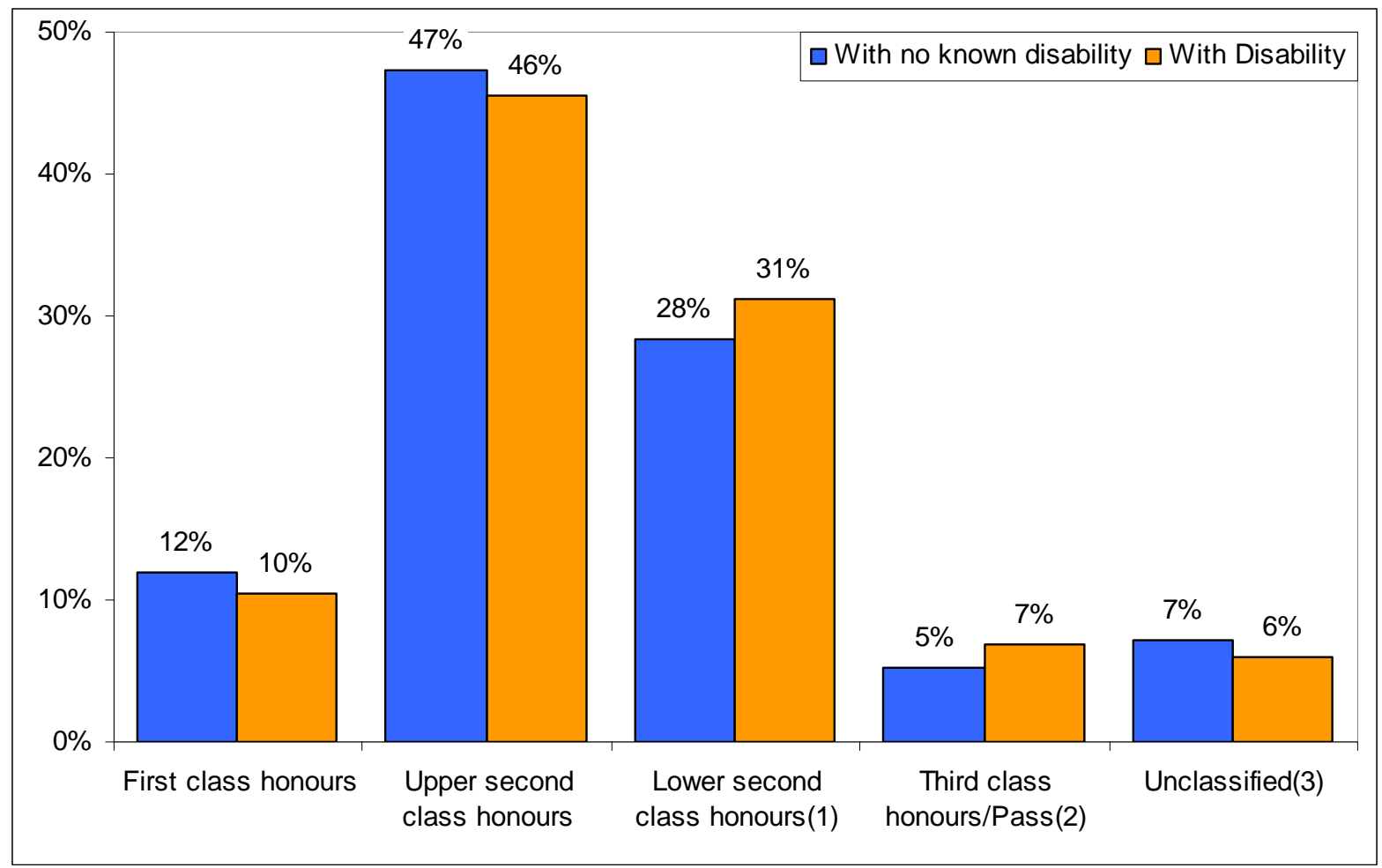

Source: HESA

Notes: (1) Lower second class honours and undivided second class honours are aggregated. (2) Third class honours, fourth class honours and pass are aggregated. (3) Unclassified, aegrotat, ordinary degree and general degree are aggregated.

\footnotetext{
${ }^{24}$ Although this finding only applied to a subset of the 2004/05 first degree qualifiers. For more details, see the report.
} 


\section{Non-Continuation Rates}

HEFCE analysis of HESA student records has shown that the proportion of full-time first degree entrants in receipt of DSA not continuing in HE after their first year in 2003/04 was $7.5 \%$. This is lower than the corresponding figure for all full time students which was $9.5 \%$. This difference was similar in 2002/03 and cannot be explained by differential subject choice and prior attainment. It is worth highlighting that these students are in receipt of support via DSA. This analysis has not been conducted for those students who report disability but are not in receipt of DSA. 


\section{The Student Experience}

Some studies have found an improvement in the experience of disabled students since the introduction of DSA and legislation specifying the responsibilities of institutions. There is still room for improvement, however, in disabled students' experiences in the areas of: (i) teaching and learning; (ii) monitoring and evaluation; and (iii) staff development.

In addition, a survey of the satisfaction of students with the quality of their courses finds that, despite high overall levels of satisfaction, disabled students tend to be slightly less positive about the quality of their course, even after controlling for a range of other factors.

\section{The Student Experience}

Riddell, Wilson and Tinklin (2004) suggest that there have been several improvements for disabled people in HE over recent years. DSA has been available universally since 1993; HEFCE and QAA provide benchmarking and codes of practice; legislation from 1992 and 2001 lays out the legal duties towards disabled students. The findings were largely supported by a number of other smaller studies.

The authors found that, since 2002, institutions have made progress in the provision made for disabled students - most institutions had a designated disability officer, for example. In addition, the needs of disabled students have been written into policies on admissions, assessments, estates and buildings and into some strategic plans. Generally disabled students seem positive about specialist support, but less so about more general services, such as generic careers advice.

Despite this, many areas needed further development, in particular teaching and learning, monitoring and evaluation, and staff development to address misleading concerns that adjusting to the needs of disabled students could undermine standards or could be seen as providing an unfair advantage.

In addition, analysis of student experience indicated that many disabled students felt isolated and lacked the social networks in which much informal learning takes place. The 'disabled' label which students need to adopt to receive DSA made it harder for them to be treated like other students does not make things easier.

\section{Results from the National Student Survey}

The aim of the National Student Survey (NSS) is to gather feedback on the quality of students' courses, to help inform the choices of future applicants to higher education, and to contribute to public accountability. The survey of final year undergraduates comprised 22 questions, grouped into six analytical scales, and a measure of overall satisfaction. The scales measure Teaching and Learning, Assessment and Feedback, Academic Support, Organisation and Management, Learning Resources and Personal Development. Surridge(2007) provides a detailed analysis of the NSS results from 2005-2007.

Table 8.1 below summarises the findings of Surridge (2008) with respect to disability. In every category, students reporting dyslexia were less positive about their experiences than those not reporting disabilities, whereas the average ratings for "other disabled" were higher than those for non-disabled in two of the categories: "Assessment and Feedback" and "Academic Support" 
Table 8.1: Summary results from NSS 2007 for full-time students by disability

\begin{tabular}{l|ccc|} 
& None & Dyslexia & Other \\
\hline $\begin{array}{l}\text { Teaching and } \\
\text { Learning }\end{array}$ & $\mathbf{4 . 0 0}$ & 3.99 & 4.02 \\
$\begin{array}{l}\text { Assessment and } \\
\text { Feedback }\end{array}$ & 3.52 & 3.46 & 3.54 \\
$\begin{array}{l}\text { Academic Support } \\
\text { Organisation and }\end{array}$ & 3.82 & 3.76 & $\mathbf{3 . 8 3}$ \\
$\begin{array}{l}\text { Management } \\
\text { Learning }\end{array}$ & $\mathbf{3 . 8 0}$ & 3.62 & 3.72 \\
$\begin{array}{l}\text { Resources } \\
\text { Personal } \\
\text { Development }\end{array}$ & $\mathbf{4 . 0 9}$ & 4.01 & 4.01 \\
$\begin{array}{l}\text { Overall } \\
\text { Satisfaction }\end{array}$ & $\mathbf{4 . 0 2}$ & 3.98 & 3.96 \\
\hline
\end{tabular}

Source: Surridge (2008)

In the same study Surridge carries out some multivariate analysis controlling for a number of student characteristics (gender, age on entry, ethnicity, disability, highest previous qualifications, term-time accommodation, domicile, response method and time), course characteristics (subject of study, franchised teaching, mode of study, qualification aim, RAE score of student's subject area) and institution characteristics (proportion of undergraduates, average A level score on intake, size of institution). The results suggested that students with dyslexia were generally less positive about their courses but overall averages remained in the "satisfied" range. 


\section{Post-HE Outcomes}

This section compares the immediate ${ }^{25}$ post-HE experiences of disabled and non-disabled graduates from Higher Education using the HESA destinations of leavers survey. Overall, qualifiers reporting a disability have marginally poorer labour market outcomes six months after qualifying - but larger differences are observed between the different types of disabilities reported.

\section{Destinations}

Response rates to the destinations of leavers survey are in the region of $80 \%$ across all disabilities. Figure 9.1 shows the main destinations 6 months after leaving HE for both disabled students and students without a disability. Qualifiers reporting a disability are less likely to go straight into employment (60\% v. 64\%) and more likely to be unemployed ( $8 \% \mathrm{v}$. $6 \%$ ). Figure 9.2 shows that this pattern can still be observed two and a half years after graduation.

Figure 9.1: First destination six months after qualifying, by disability, 2006/07 (\% of Full time UK domiciled first degree graduates in each category)

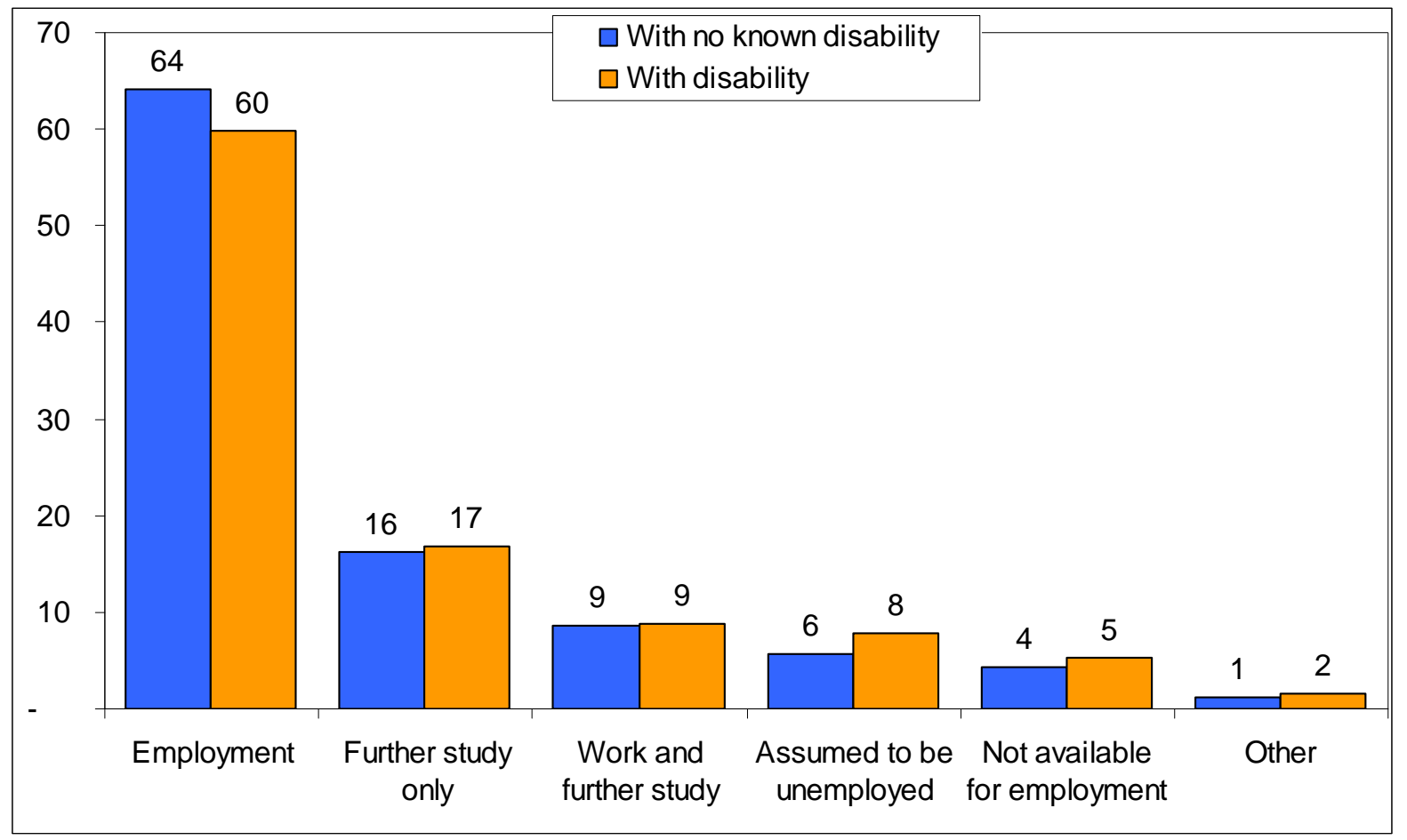

Source: HESA

\footnotetext{
${ }^{25}$ A detailed discussion of labour market outcomes for those with and without disabilities in the wider working age population is beyond the scope of this report. A more general discussion of labour market outcomes for disabled people can be found in http://www.officefordisability.gov.uk/research/eedp.asp.
} 
Figure 9.2: First destination 2.5 years after qualifying in 2002/03, by disability, (\% of Full time UK domiciled first degree graduates in each category)

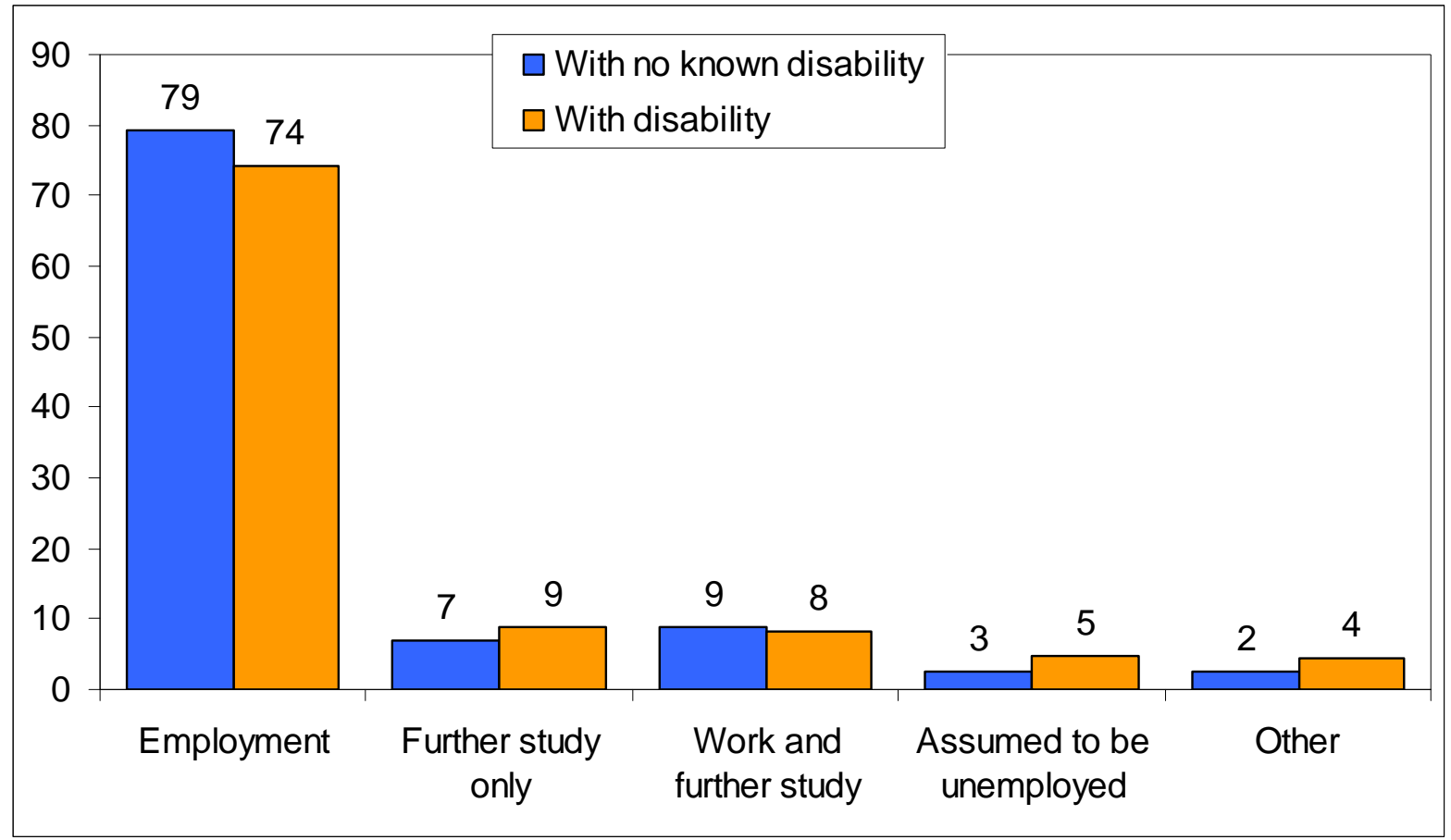

Source: HESA

\section{Unemployment}

The proportion unemployed six months after qualifying varies between the different disabilities. Figure 9.2 below gives the breakdown by disability, compared to the figure of $6 \%$ for qualifiers without a disability. Students with mobility difficulties or who require personal care support appear most likely to be unemployed (14\% and $18 \%$ respectively).

Figure 9.2: Percentage assumed unemployed six months after qualifying, by type of disability, 2005/06 (FT UK domiciled students)

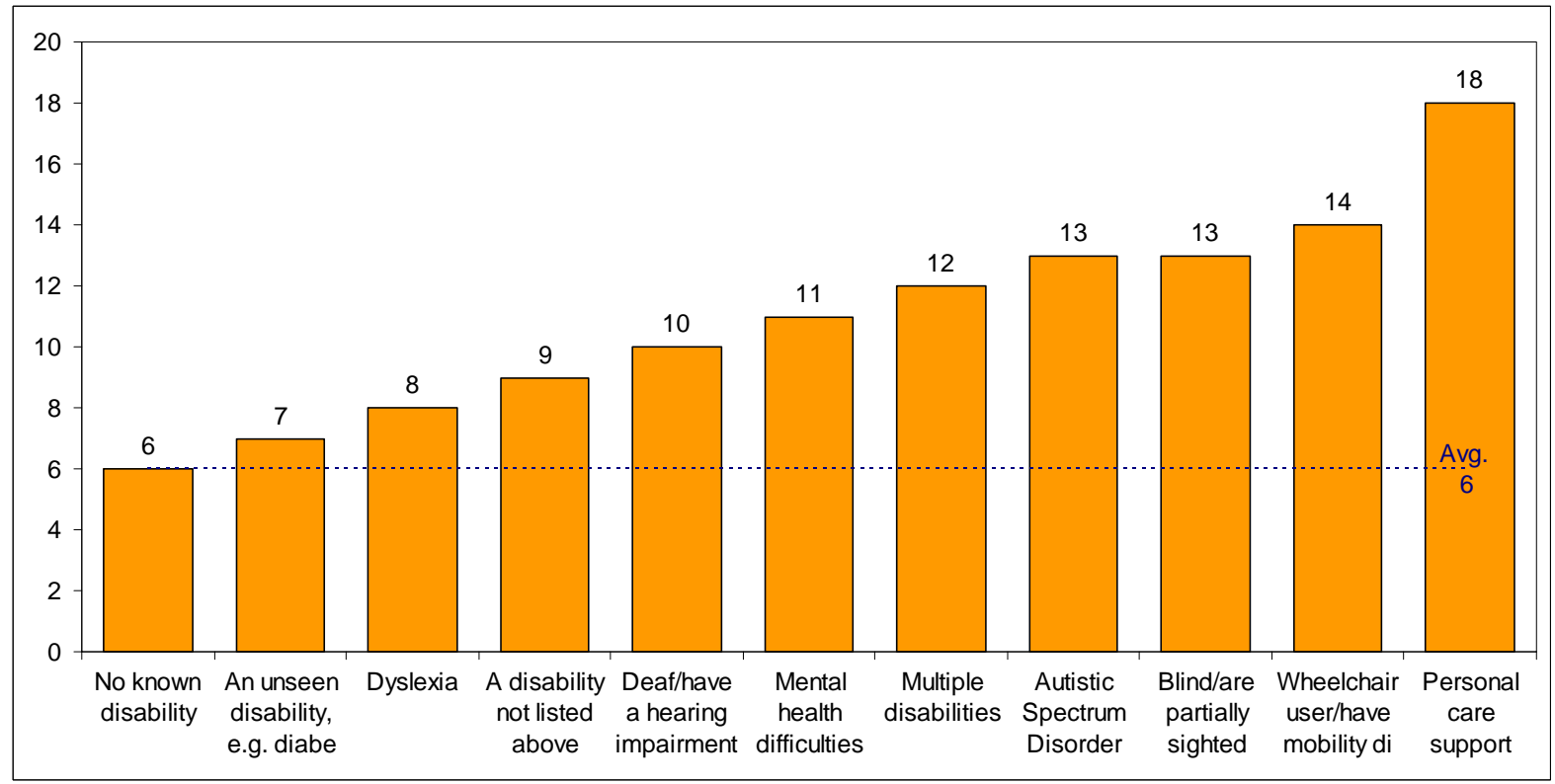

Source: HESA 
HESA data also shows that the subject choice of disabled students does not appear to explain this difference, with disabled graduates being more likely to be unemployed for most subjects. It is important to recognise that none of these comparisons take account of other factors (such as differential degree attainment seen in section 7) which may explain labour market outcomes.

\section{Type of Employment}

Of those in employment, disabled qualifiers are slightly less likely than those without disabilities to be in permanent employment 6 months after qualifying (49\% compared to $51 \%)$. Again, however, the difference between various types of disability tends to be larger than that between those with and without disabilities. Only $41 \%$ of students with mobility difficulties are in permanent employment, compared with $52 \%$ of students with a hearing difficulty and $53 \%$ of students who are visually impaired.

The same holds for the proportion of students who are in jobs where a degree is a formal requirement. In 2005/06, 26\% of disabled students were in such jobs, compared to $28 \%$ of students without disabilities - but only $18 \%$ of qualifiers with mental health difficulties were in jobs where a degree is a formal requirement.

\section{Salary}

Although the destinations of leavers survey data suggests that disabled students tend, on average, to earn marginally less than students without a disability, average salary information needs to be interpreted with caution due to low response rates to this particular question. Only around $40 \%$ of those who are employed and have responded to the DLHE provide information on their current salary.

\section{Labour Market Outcomes}

More substantial research has examined labour market outcomes for disabled students, in particular the "What happens next?" report published by the Association of Graduate Careers Advisory Services (2004) which analysed HESA destinations data. This is supplemented by findings from work undertaken by Burchardt (2005) who analysed of the 1970 Birth Cohort Study, the YCS and some primary research, and from a literature review and analysis of HESA data undertaken by Parker et al. (2006)

A key finding from Burchardt (2005) was that the scope and aspirations among disabled 16 year olds were similar to those of their non-disabled counterparts in terms of plans for further education, job and earnings aspirations - though that this refers to all young people, not just those going into HE. This mirrors our finding in Section 1 that disabled 17 year olds appeared to have similar aspirations about going to university as their peers without disabilities. 


\section{REFERENCES AND BIBLIOGRAPHY}

Association of Graduate Careers Advisory Service Disabilities Task Group (2006): "What Happens Next? A Report on the first Destinations of 2004 Graduates with Disabilities"

Burchardt, T. (2005): “The education and employment of disabled young people.", Joseph Rowntree Foundation

DfES (2007): "Ethnicity and Degree Attainment", DfES research report RW92, http://www.dfes.gov.uk/research/data/uploadfiles/RW92.pdf

DfES (2006): "Student Income and Expenditure Survey 2004/05" Research report RR725, http://www.dfes.gov.uk/research/data/uploadfiles/RR725.pdf

DIUS (2008): "Participation Rates in Higher Education: Academic Years 1999/2000-2006/07 (Provisional)", Statistical First Release 02/2008, http://www.dcsf.gov.uk/rsgateway/DB/SFR/s000780/index.shtml

DIUS (2008): "Gender Gaps in Higher Education Participation - An Analysis of the Relationship between Prior Attainment and Young Participation by Gender, Socio-Economic Class and Ethnicity", DIUS Research Report 0814.

HEFCE: Higher Education Funding Council for England, performance indicators. http://www.hefce.ac.uk/learning/perfind/

HEFCE response to Parliamentary Written Question 90228, http://www.publications.parliament.uk/pa/cm200506/cmhansrd/cm061009/text/61009w0024.h $\underline{\operatorname{tm} \# 06101116000014}$

HESA (1): Higher Education Statistics Agency, Students and Qualifiers, http://www.hesa.ac.uk/holisdocs/pubinfo/stud.htm

HESA (2): Higher Education Statistics Agency, Performance indicators, http://www.hesa.ac.uk/pi/home.htm

HESA (3): Higher Education Statistics Agency, Destination of leavers survey, http://www.hesa.ac.uk/holisdocs/pubinfo/destinations.htm

Evramidis, E., and D. Skidmore (2004): "Reappraising learning support in higher education. \& Research in Post-Compulsory Education, 9.1".

Fuller, M., M. Healey, A. Bradley and T. Hall: (2004), "Barriers to learning: a systematic study of the experience of disabled students in one university. Studies in HE", 29.3.

Fuller, M., S. Riddell and A. Bradley: Enhancing the quality and outcomes of disabled students' learning in HE., University of Edinburgh (ongoing research)

Gannon-Leary, P. and Smailes, J: (2004), "Students with dyslexia: research projects at Northumbria University", Widening Participation \& Lifelong Learning, Vol 6.2.

National Disability Team, and Skill: National Bureau for Students with Disabilities (2004):

"Aspiration raising and transition of disable students from further to higher education", (2004)

Parker, G., Pascal, G and Hendey, N: (2006), "Double Discrimination? Gender and disability in access to the labour market". G.Parker et al, University of York (2006) 
Ramsden, B. (2005): "Participation in Higher Education: A Study to Determine Whether the Higher Education Initial Participation Rate Should be Disaggregated", Department for Education and Skills Research Report RR676 http://www.dfes.gov.uk/research/data/uploadfiles/RR676.pdf

Richardson, J. (2001): "The representation and attainment of students with a hearing loss in higher education", Studies in HE, 26.2.

Riddell, S., A. Wilson and T. Tinklin: (2004), "Disabled Students and Multiple Policy Innovation in Higher Education", ESRC, (2004)

Riddell, S., A. Wilson T. and Tinklin: (2002), "Disability and the wider access agenda: supporting disabled students in different institutional contexts". Widening Participation and Lifelong Learning, 4.3.

Sanderson, A. (2001): "Disabled students in transition: A tale of two sectors' failure to communicate". Journal of Further and Higher Education, Vol 25.2.

Surridge, P. (2008): “The National Student Survey 2005-2007: Findings and trends", HEFCE. http://www.hefce.ac.uk/pubs/rdreports/2008/rd12_08/

Tinklin, T., S. Riddell and, A. Wilson (2004): "Policy and provision for disabled students in higher education in Scotland and England: the current state of play." Studies in HE, 29.5.

Tozer, N. (2006): "The Snowdon Survey 2006", The Snowdon Award Scheme,

UCAS, Universities and Colleges' Admissions Service, Applications and Acceptances, http://www.ucas.ac.uk/figures/data/index.html

Youth Cohort Study, Cohorts 10, 11, 12, 13 


\section{APPENDIX}

\section{Data sources}

This paper uses data from a range of sources including the Youth Cohort Study (YCS), the Universities and Colleges' Admissions service (UCAS), the Higher Education Statistics Agency (HESA), the National Pupil Database (NPD), and, the Student Expenditure and Income Survey (SIES). This section briefly describes the characteristics of the data sources, what information they provide and the problems associated with each source relating to information on disability.

\section{Youth Cohort Study (YCS)}

The Youth Cohort Studies are a series of longitudinal surveys among young people aged 16 and upwards, which monitor their decisions and behaviour in making the transition from compulsory education to further or higher education, employment or another activity. YCS cohorts are selected by taking a sample designed to be representative of all Year 11 pupils in England and Wales (excluding those in special schools). The first survey (or 'sweep') of those sampled takes place one year later, with subsequent sweeps at varying time intervals (usually annually but occasionally after shorter intervals). Subsequent sweeps are weighted to account for students who drop out of the education system so should be, as far as possible, representative of the population surveyed at age $16^{26}$. To date, there have been 11 YCS Cohorts (a $12^{\text {th }}$ is currently underway) and more than 36 sweeps.

YCS respondents report whether or not they are disabled; they are not asked about the type of disability. There is considerable volatility over time in the reporting of disability and the sample sizes tend to be small, so that detailed analysis of some of the routed questions is often not possible. Any analysis of the disabled group is subject to fairly wide confidence intervals. The YCS gives us some understanding of the differences between the disabled and non-disabled group within a cohort. Data from successive cohorts cannot be used to reliably infer trends in these differences.

Table A1 below shows that there is also considerable volatility in the reporting of disability by the same individuals over time in the YCS. Only about 1 in 10 individuals who ever report a disability report being disabled in all three sweeps (1, 3 and 4). In other words, of the entire cohort, only $1.2 \%$ consistently report being disabled at ages 16/17, 18/19 and 19/20. One in five reports being disabled only at age $19 / 20$. 10\% of individuals at age 19/20 had reported a disability in at least one of the sweeps (not shown in the table). While some of this volatility will be due to reporting error, some will reflect a genuine change in whether or not the respondent considers him or herself to have a disability. Certain types of disability fluctuate, with levels of severity that vary over time.

\footnotetext{
${ }^{26}$ There is a danger that despite this weighting some students are more likely to drop out than others, or that the responses by those who remain in education will not represent those who have dropped out
} 
Table A1: Pattern of disability reporting

\begin{tabular}{cccc}
\hline \multicolumn{2}{c}{ Reported disability at: } & $\begin{array}{c}\text { \% of all in sweep 4 who reported a disability } \\
\text { at least once in Cohort 11 }\end{array}$ \\
\hline Age 16/17 & Age 18/19 & Age 19/20 & $27 \%$ \\
\hline$\checkmark$ & & & $13 \%$ \\
& $\checkmark$ & $\checkmark$ & $22 \%$ \\
$\checkmark$ & $\checkmark$ & & $8 \%$ \\
$\checkmark$ & & $\checkmark$ & $7 \%$ \\
& $\checkmark$ & $\checkmark$ & $11 \%$ \\
\hline$\checkmark$ & $\checkmark$ & $\checkmark$ & $11 \%$
\end{tabular}

When looking at the results from the YCS presented later, the reader should bear in mind that disability is difficult to measure. Furthermore, the YCS was not designed to support detailed analyses of disabled young people. Finally, although we may refer to "disabled students", one should remember that what we really mean are "students who report a long standing illness, disability or infirmity".

Cohort 11 of the YCS suggests that the proportion of individuals reporting a disability varies between $4.2 \%$ and 5.3\%, depending upon the sweep looked at as shown in Table A2.

Table A2: Proportion of YCS Cohort 11 respondents reporting a disability at each age

\begin{tabular}{lcccc}
\hline Age of respondents & $\mathbf{1 6}$ & $\mathbf{1 7}$ & $\mathbf{1 8}$ & $\mathbf{1 9}$ \\
\hline Interviewed (spring of year) & 2002 & - & 2004 & 2005 \\
Number with disability (weighted) & 742 & - & 328 & 327 \\
Number with disability (unweighted) & 640 & - & 267 & 254 \\
Total number (weighted) & 16,707 & - & 7,777 & 6,180 \\
\hline Proportion with disability (weighted) & $\mathbf{4 . 4 \%}$ & - & $\mathbf{4 . 2 \%}$ & $\mathbf{5 . 3 \%}$ \\
\hline
\end{tabular}




\section{UCAS Data}

The Universities and Colleges' Admissions Service (UCAS) publish data relating to the annual number of applicants and accepted applicants to its member institutions. It is collected from the application form completed by each applicant. Provision of information on disability is voluntary and applicants are advised they may choose only to inform the institutions to which they apply directly. Disability data are available only for home (UKdomiciled) applicants on full-time undergraduate courses.

There are some discontinuities in the data: for 2003 entry, the "dyslexia" category has been extended to other specific difficulties (including dyslexia); the "personal care support" category has been abolished; and a further, "autistic disorder", category has been introduced.

\section{HESA Data}

The Higher Education Statistics Agency (HESA) maintains a database of staff and student records for all UK Higher Education Institutions (HEIs). The HESA student record includes information on self-reported disability including type of disability. It also contains information on the number of students that report receipt of Disabled Students' Allowances (DSAs) to their institution. Again disability is self-reported so it will suffer from the same weakness as the UCAS data, and it becomes virtually impossible to disentangle changes in the numbers of students reporting a disability from actual changes in the proportion of students who are disabled. Equally changes in perceptions about eligibility for DSAs may change the proportion of students that report their disability to their institution. DSA receipt is considered the more robust of the HESA disability indicators and is used in their performance indicators ${ }^{27}$.

The proportion of students who are in receipt of DSA is less than the proportion who are recorded as disabled ${ }^{28}$. It is noteworthy that students do not have to inform their institution that they are in receipt of DSA and so potentially there could be a substantial undercount of the numbers involved. But HESA do not believe this to be a major problem. This may however affect changes over time, i.e. an increase in the level of DSA may incentivise more claimants.

As for the type of disability recorded by the HESA, comparisons with the UCAS data become very difficult since the HESA data never introduced a "learning difficulty" category. Overall, it would appear that there is some overlap between the HESA ("Unseen" + "Dyslexia" + "Other") categories and the UCAS ("Unseen" + "Dyslexia" / "Learning Difficulty" + "Other") categories. Together, these 3 categories account for around $82 \%$ of all reported disabilities on both datasets (2004/05 data).

\section{NPD Data}

The National Pupil Database (NPD) is compiled by the department for Children Schools and Families (DCSF) and it contains information from :(i) school censuses covering the characteristics of pupils in maintained schools in England, (ii) Key stage test results covering pupils attainment up to (and including) A levels, (iii) matched information from the Learning and Skills Council's Individualised Learner Record covering information about those in FE, and (iv) matched information from the HESA's Student Record. The school census contains information about pupils Special Educational Needs (SEN) and we have used information for

\footnotetext{
${ }^{27}$ http://www.hesa.ac.uk/pi/home.htm

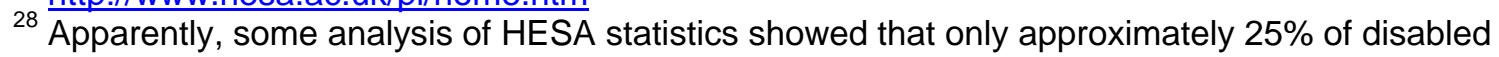
students were in receipt of the DSA (Tinklin, Riddell and Wilson (2001).
} 
the cohort of pupils in year 11 in 2001/02 ${ }^{29}$ their KS5 (A level) records for 2003/04 and the matched HESA records for 2004/05 and 2005/06. SEN is not a definition of disability but some pupils with SEN will have disabilities that affect their ability to learn in a traditional school environment, but many disabled pupils will not have SEN.

\section{SIES data}

The Student Income and Expenditure Survey (SIES) collects information on sources and levels of student income and expenditure, debt, savings and financial hardship. Whilst the main report does not include a separate breakdown by disability, the dataset does record whether a student is in receipt of disability allowances. The analysis covered in this paper is for England only.

Table A3 summarises the basic characteristics of those in receipt of DSA and the general population. DSA students seem slightly less likely to be amongst the youngest age group but given the size of sample this is not a major cause for concern. The similarity between the groups is reassuring for the subsequent analysis, as it means that observed differences are more likely to be associated with disability rather than other circumstantial and personal characteristics.

Table A3: Basic characteristics of students with and without DSA

\begin{tabular}{llrr}
\hline Characteristics & All FT & $\begin{array}{r}\text { In receipt } \\
\text { of DSA }\end{array}$ \\
\hline Gender & Male & $46 \%$ & $46 \%$ \\
& Female & $54 \%$ & $54 \%$ \\
\hline Age group at start of course & Under 20 & $60 \%$ & $50 \%$ \\
& $21-24$ & $28 \%$ & $38 \%$ \\
& 25 or over & $12 \%$ & $12 \%$ \\
\hline Social class & Managerial and professional & $57 \%$ & $59 \%$ \\
& Intermediate & $21 \%$ & $13 \%$ \\
& Routine and manual + & $22 \%$ & $28 \%$ \\
\hline Family situation & unemployed & $3 \%$ & $4 \%$ \\
& Two adult family & $2 \%$ & $2 \%$ \\
& Lone parent & $5 \%$ & $5 \%$ \\
& Couple & $89 \%$ & $89 \%$ \\
\hline Dependency & Single & $82 \%$ & $76 \%$ \\
& Dependent & $18 \%$ & $24 \%$ \\
\hline Ethnicity & Independent & $87 \%$ & $88 \%$ \\
& White & $5 \%$ & $3 \%$ \\
& Asian or Asian British & $3 \%$ & $2 \%$ \\
& Black or Black British & $5 \%$ & $7 \%$ \\
\hline Living at home & Mixed Other & $18 \%$ & $17 \%$ \\
& Yes & $82 \%$ & $83 \%$ \\
\hline
\end{tabular}

\footnotetext{
${ }^{29}$ This is the first year of the school census and data quality is not as good as in subsequent years. But, we believe it is good enough to give a good indication of the patterns.
} 
Figures A1.1 and A1.2 show a similarity of attitudes towards HE between disabled students and all full time students.

\section{Figure A1.1: Attitudes towards HE for all full time students}

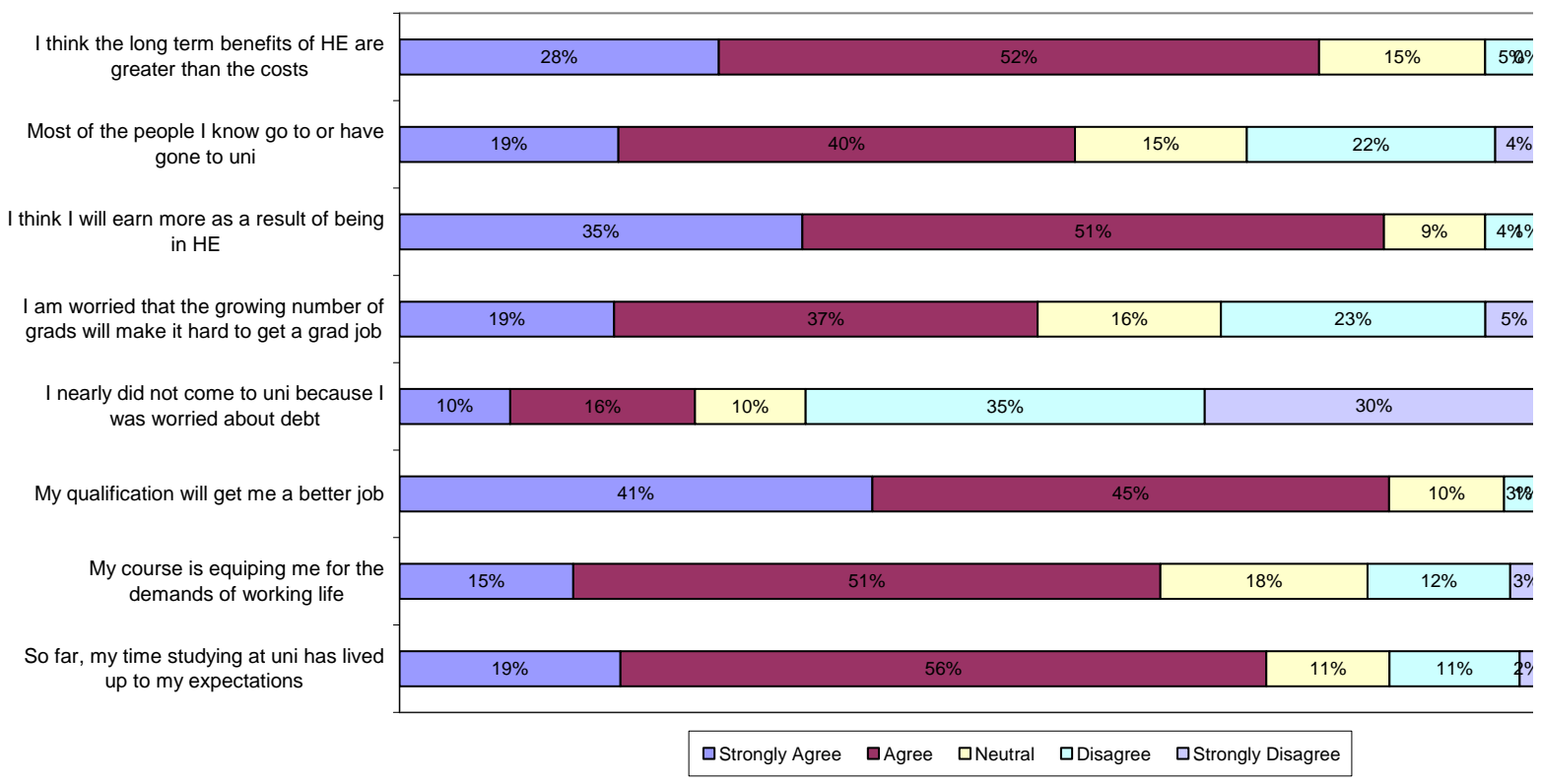

Figure A1.2: Attitudes towards HE for full time students in receipt of DSA

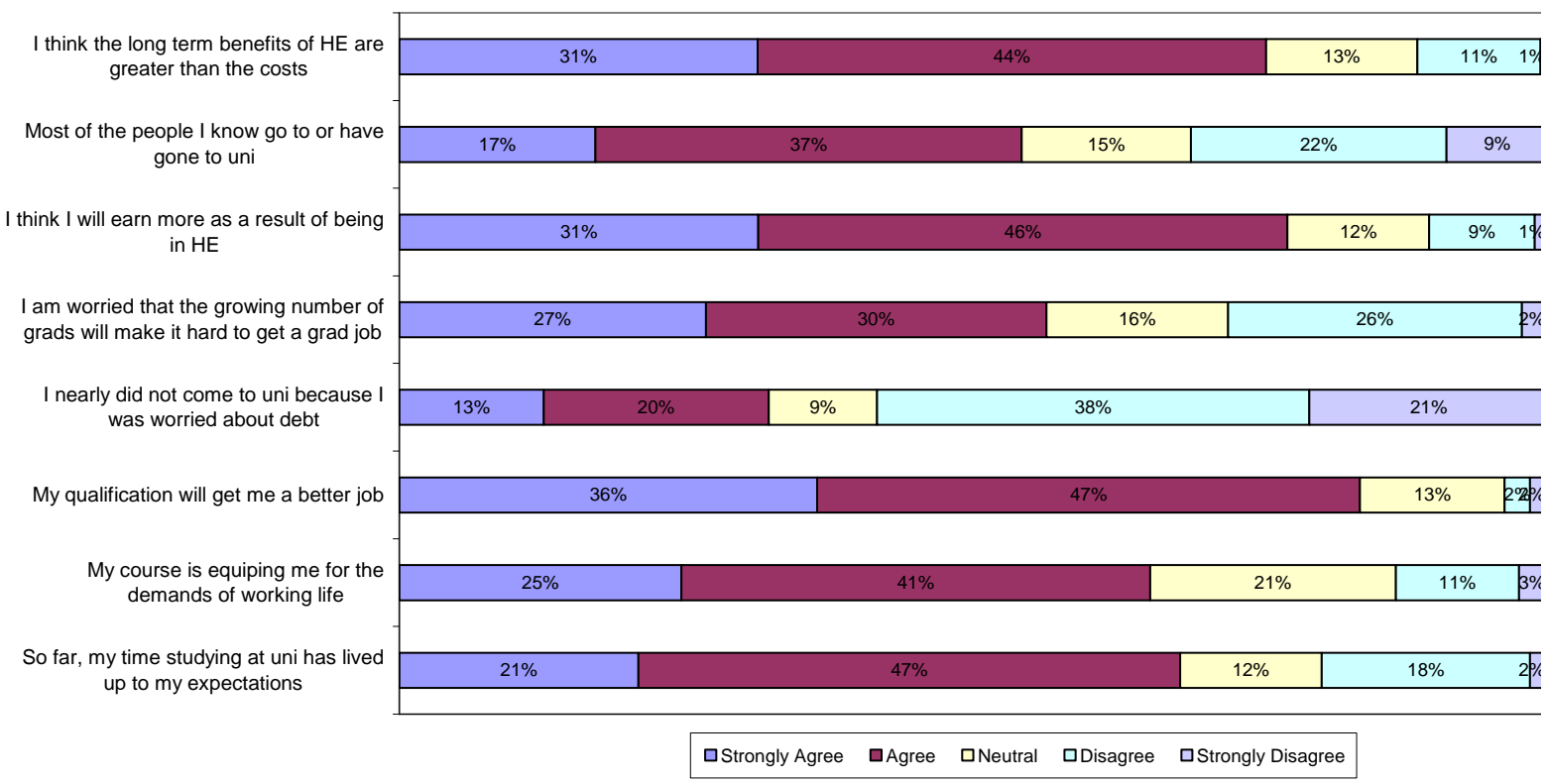




\section{Prior attainment and young HE participation by SEN in detail}

In this section we present the results of several logistic regressions which we have carried out using the NPD and HESA matched records. This dataset has the advantage of being very large containing over 550 thousand records. This enables a much more detailed examination of the role of prior attainment than is possible using the Survey data sources. We find that using more sophisticated specifications of attainment (as opposed to simply looking within broad attainment groups such as $5 A^{*}-C$ of $2+A$ levels) there is little difference in participation rates by SEN status for similarly qualified young people.

Table A4 summarises the results of four logistic regression models that estimate the association between SEN and HE participation. Model 1 is the "raw" relationship, and shows a relatively strong negative effect. The other models progressively add GCSE (2) and A level (3) control variables. In these models the size of the effect is markedly reduced. In model (4) we also take into account pupils ethnicity and income deprivation based on their home postcode in 2001/02. In this final specification there is very little variation in the probability of HE participation that can be explained by SEN. If anything there appears to be a slightly greater tendency for those with SEN to participate in higher education. This latter result is of little substantive significance as the estimate is equivalent to a $1 \%$ change in the probability of participation in HE by 19 for a representative person with the average characteristics.

Figure A2 demonstrates this slight positive effect, but overall within similar levels of GCSE attainment the HE participation rates for those with and without SEN are similar. The raw gap in participation is driven by the large numbers of people with SEN who do not have high GCSE attainment shown by the dotted line in the figure A1.3.

Table A4 Logistic regression results exploring the association between attainment and HE participation for young people with SEN

Dependent variable participation in Higher Education by age 19

(3)

\begin{tabular}{|c|c|c|c|c|}
\hline $\begin{array}{l}\text { SEN statement } \\
\text { vs No SEN }\end{array}$ & -2.49 & 0.23 & -0.06 & 0.10 \\
\hline Standard error & $(-74.36)^{\star \star \star}$ & $(5.27)^{\star \star \star}$ & $(-1.46)$ & $(2.13)^{\star}$ \\
\hline $\begin{array}{l}\text { SEN without } \\
\text { statement vs no } \\
\text { SEN }\end{array}$ & -1.63 & 0.15 & 0.07 & 0.10 \\
\hline Standard error & $(-134.21)^{\star \star \star}$ & $(9.70)^{\star \star \star}$ & $(4.40)^{\star \star \star}$ & $(5.62)^{\star \star \star}$ \\
\hline GCSE & No & $\begin{array}{l}\text { Yes } \\
\text { linear }\end{array}$ & $\begin{array}{l}\text { Yes } \\
\text { linear }\end{array}$ & $\begin{array}{c}\text { Yes } \\
\text { polynomial }\end{array}$ \\
\hline $\begin{array}{l}\text { A Level } \\
(2003 / 04)\end{array}$ & No & No & $\begin{array}{l}\text { Yes } \\
\text { linear }\end{array}$ & Yes polynomial \\
\hline $\begin{array}{l}\text { Ethnicity + } \\
\text { Deprivation }\end{array}$ & No & No & No & Yes \\
\hline Log-likelihood & -321834.5 & -206516.5 & -178538.3 & -170173.6 \\
\hline $\mathrm{N}$ & 556685 & 556685 & 556685 & 549528 \\
\hline Pseudo R2 & 0.0521 & 0.392 & 0.474 & 0.493 \\
\hline
\end{tabular}


Figure A2 Participation in HE by 19 for detailed GCSE attainment and SEN

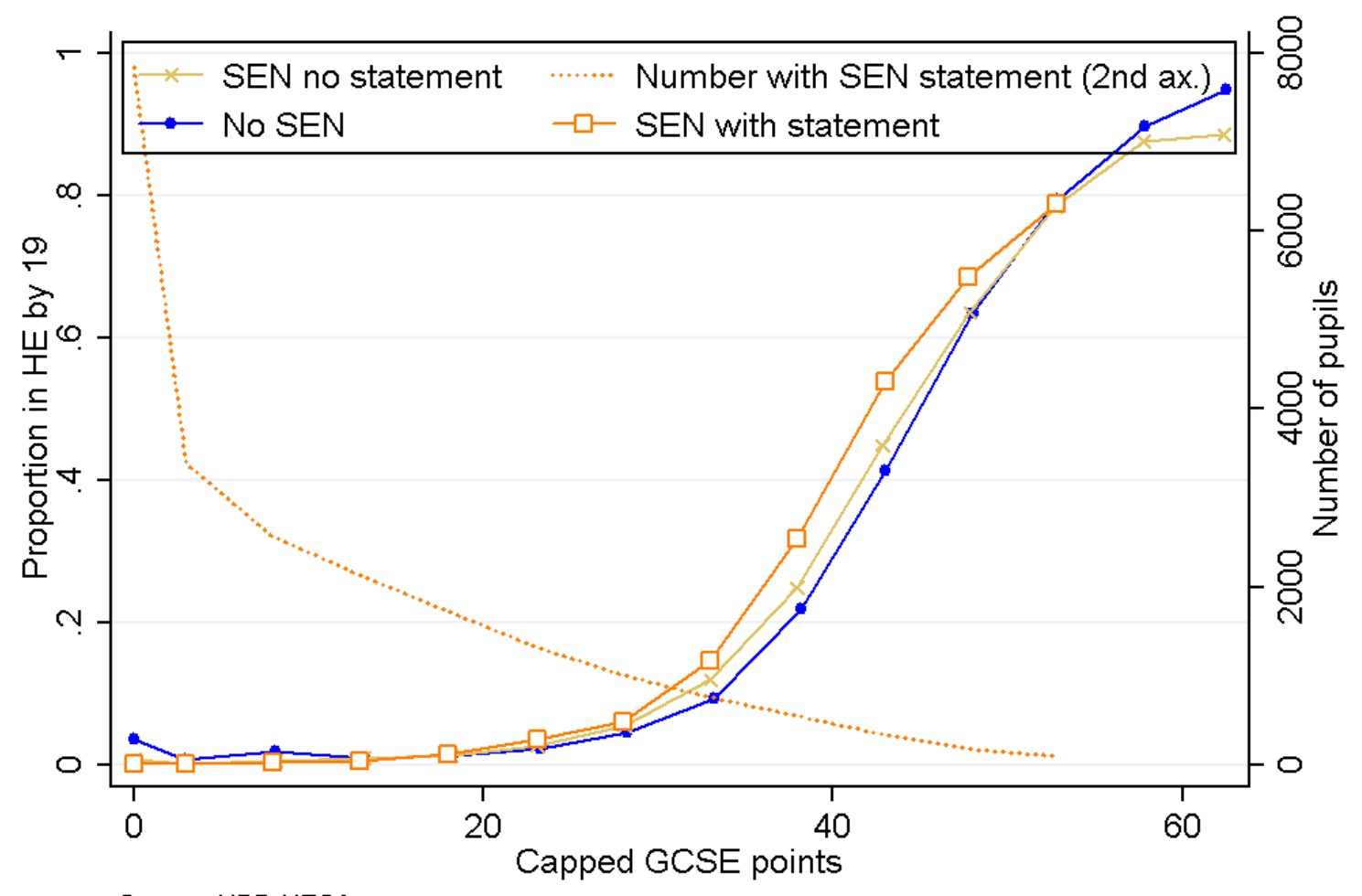

Source: NPD-HESA

Categories with fewer than 100 cases omitted. 
Ref: DIUS Research Report 09-06

(C) Crown Copyright 2009

www.dius.gov.uk/research

Published by the Department for Innovation,

Universities and Skills

Department for Innovation, Universities \& Skills 